Keywords: Neutralization, Used Nuclear Fuel,

Gadolinium, Aluminum

Retention: Permanent

\title{
Neutralizations of High Aluminum Low Uranium Used Nuclear Fuel Solutions Containing Gadolinium as a Neutron Poison
}

K. M. L. Taylor-Pashow

June 2011

Savannah River National Laboratory

Savannah River Nuclear Solutions, LLC

Aiken, SC 29808

Prepared for the U.S. Department of Energy under contract number DE-AC09-08SR22470.

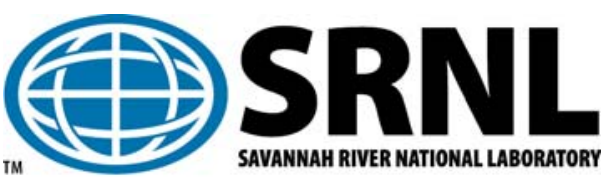


SRNL-STI-2011-00316

Revision 0

\section{DISCLAIMER}

This work was prepared under an agreement with and funded by the U.S. Government. Neither the U.S. Government or its employees, nor any of its contractors, subcontractors or their employees, makes any express or implied:

1. warranty or assumes any legal liability for the accuracy, completeness, or for the use or results of such use of any information, product, or process disclosed; or

2. representation that such use or results of such use would not infringe privately owned rights; or

3. endorsement or recommendation of any specifically identified commercial product, process, or service.

Any views and opinions of authors expressed in this work do not necessarily state or reflect those of the United States Government, or its contractors, or subcontractors.

\section{Printed in the United States of America \\ Prepared for \\ U.S. Department of Energy}




\section{REVIEWS AND APPROVALS}

AUTHORS:

K. M. L. Taylor-Pashow, Separations and Actinide Science Programs

Date

TECHNICAL REVIEW:

M. G. Bronikowski, Separations and Actinide Science Programs

Date

APPROVAL:

S. D. Fink, Manager

Date

Separations and Actinide Science Programs

S. L. Marra, Manager

Date

Environmental \& Chemical Process Technology Research Programs

W. G. Dyer, Outside Facilities \& Technical Support Manager

Date 
SRNL-STI-2011-00316

Revision 0

\section{EXECUTIVE SUMMARY}

H-Canyon will begin dissolving High Aluminum - Low Uranium (High A1/Low U) Used Nuclear Fuel (UNF) following approval by DOE which is anticipated in CY2011. High Al/Low $\mathrm{U}$ is an aluminum/enriched uranium UNF with small quantities of uranium relative to aluminum. The maximum enrichment level expected is $93 \%{ }^{235} \mathrm{U}$. The High Al/Low U UNF will be dissolved in $\mathrm{H}$-Canyon in a nitric acid/mercury/gadolinium solution. The resulting solution will be neutralized and transferred to Tank $39 \mathrm{H}$ in the Tank Farm. To confirm that the solution generated could be poisoned with Gd, neutralized, and discarded to the Savannah River Site (SRS) high level waste (HLW) system without undue nuclear safety concerns the caustic precipitation of simulant solutions was examined.

Experiments were performed with three simulant solutions representative of the H-Canyon estimated concentrations in the final solutions after dissolution. The maximum $\mathrm{U}, \mathrm{Gd}$, and $\mathrm{Al}$ concentration were selected for testing from the range of solution compositions provided. Simulants were prepared in three different nitric acid concentrations, ranging from 0.5 to $1.5 \mathrm{M}$. The simulant solutions were neutralized to four different endpoints: 1) just before a solid phase was formed ( $\mathrm{pH} \mathrm{3.5-4),2)} \mathrm{the} \mathrm{point} \mathrm{where} \mathrm{a} \mathrm{solid} \mathrm{phase} \mathrm{was} \mathrm{obtained,} \mathrm{3)} 0.8 \mathrm{M}$ free hydroxide, and 4) $1.2 \mathrm{M}$ free hydroxide, using $50 \mathrm{wt} \%$ sodium hydroxide $(\mathrm{NaOH})$.

The settling behavior of the neutralized solutions was found to be slower compared to previous studies, with settling continuing over a one week period. Due to the high concentration of Al in these solutions, precipitation of solids was observed immediately upon addition of $\mathrm{NaOH}$. Precipitation continued as additional $\mathrm{NaOH}$ was added, reaching a point where the mixture becomes almost completely solid due to the large amount of precipitate. As additional $\mathrm{NaOH}$ was added, some of the precipitate began to redissolve, and the solutions neutralized to the final two endpoints mixed easily and had expected densities of typical neutralized waste. Based on particle size and scanning electron microscopy analyses, the neutralized solids were found to be homogeneous and less than 20 microns in size. The majority of solids were less than 4 microns in size.

Compared to previous studies, a larger percentage of the $\mathrm{Gd}$ was found to precipitate in the partially neutralized solutions (at $\mathrm{pH} 3.5-4$ ). In addition the Gd:U mass ratio was found to be at least 1.0 in all of the solids obtained after partial or full neutralization. The hydrogen to $\mathrm{U}(\mathrm{H}: \mathrm{U})$ molar ratios for two accident scenarios were also determined. The first was for transient neutralization and agitator failure. Experimentally this scenario was determined by measuring the $\mathrm{H}: \mathrm{U}$ ratio of the settled solids. The minimum H:U molar ratio for solids from fully neutralized solutions was 388:1. The second accident scenario is for the solids drying out in an unagitiated pump box. Experimentally, this scenario was determined by measuring the H:U molar ratio in centrifuged solids. The minimum H:U atom ratios for centrifuged precipitated solids was 250:1. It was determined previously that a $30: 1 \mathrm{H}: \mathrm{Pu}$ atom ratio was sufficient for a 1:1 Gd:Pu mass ratio. Assuming a $1: 1$ equivalence with ${ }^{239} \mathrm{Pu}$, the results of these experiments show $\mathrm{Gd}$ is a viable poison for neutralizing $\mathrm{U} / \mathrm{Gd}$ solutions with the tested compositions. 


\section{TABLE OF CONTENTS}

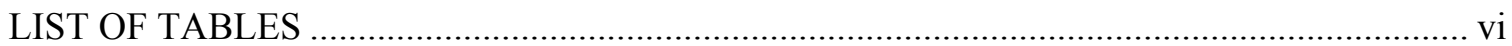

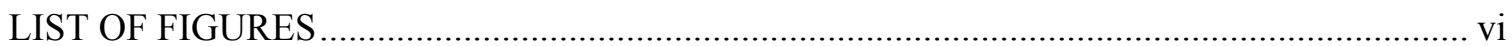

LIST OF ABBREVIATIONS ..................................................................................... viii

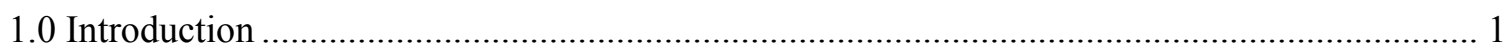

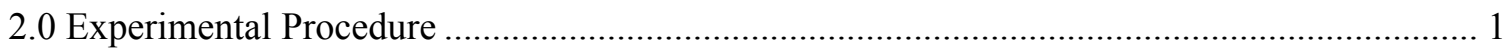

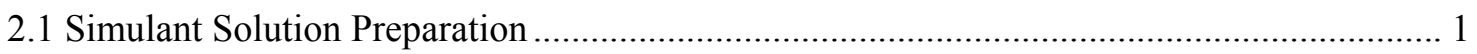

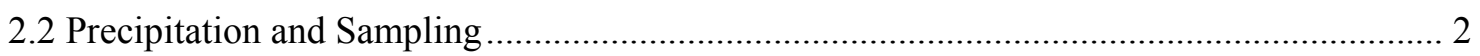

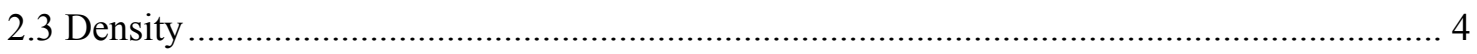

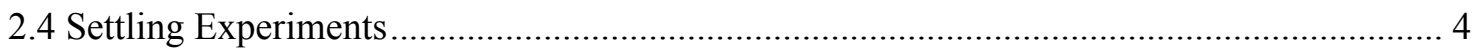

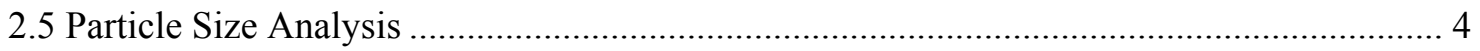

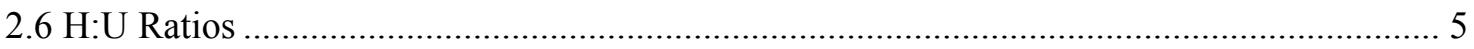

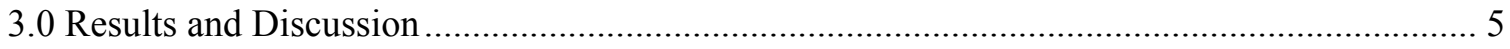

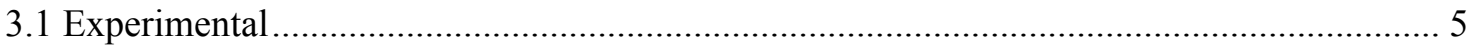

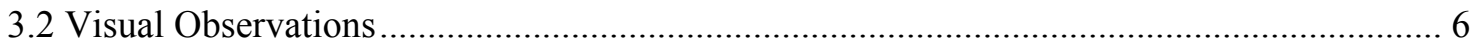

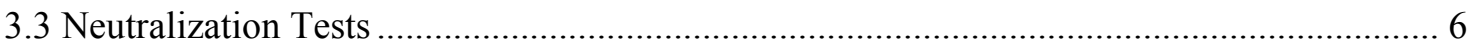

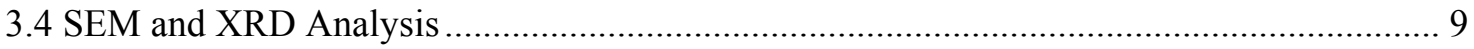

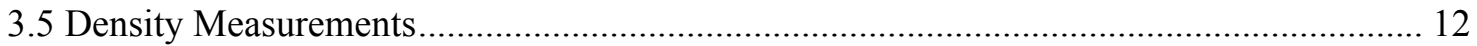

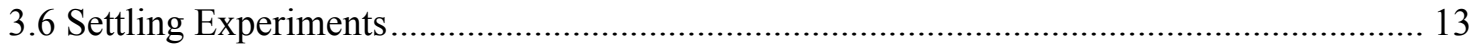

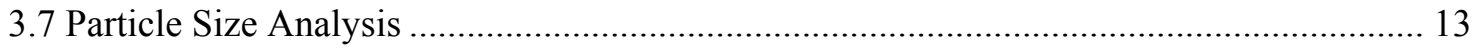

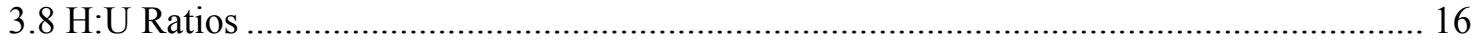

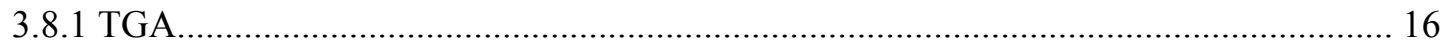

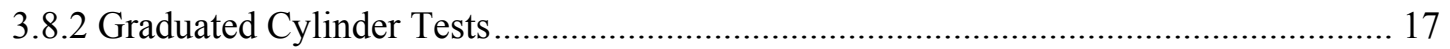

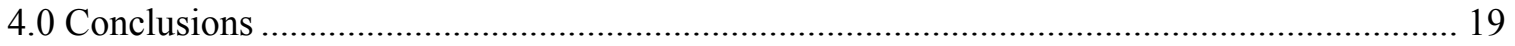

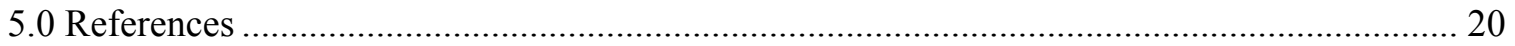

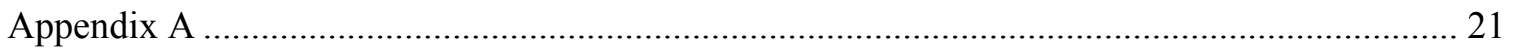

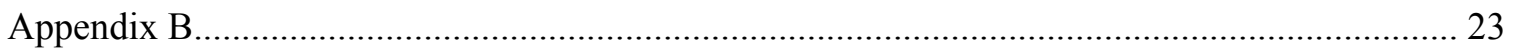

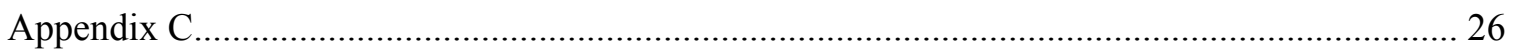

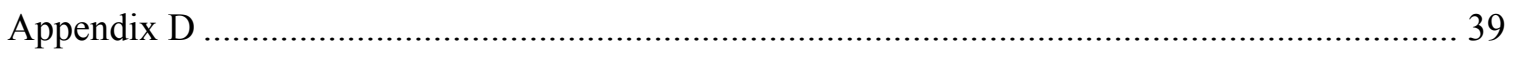

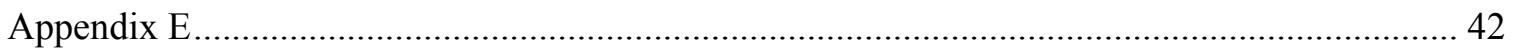




\section{LIST OF TABLES}

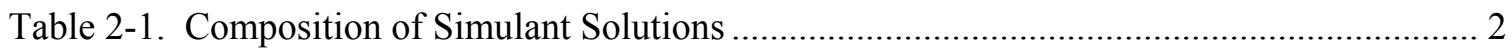

Table 2-2. Volume of $\mathrm{NaOH}$ Added for Each Test ..................................................................... 2

Table 2-3. Summary of Samples Removed During Cold Test ..................................................... 4

Table 3-1. Gd:U Mass Ratios in the Neutralized Solutions ...................................................... 7

Table 3-2. Percentage of Each Element Precipitated from Solution Upon Neutralization ${ }^{\mathrm{a}}$........... 8

Table 3-3. Percentage of Each Element Precipitated from Solution upon Neutralization of

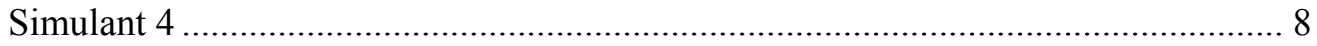

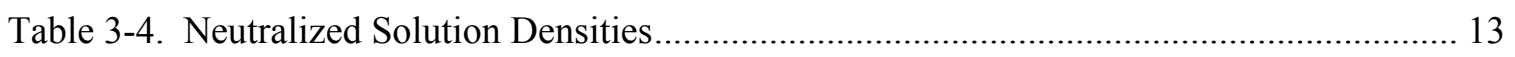

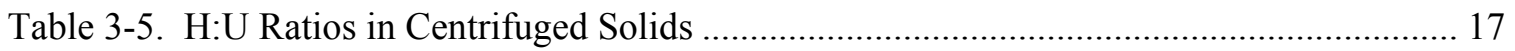

Table 3-6. H:U Molar Ratios in One-Week Settled Solids ....................................................... 18

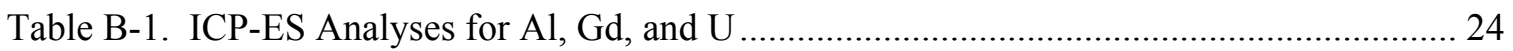

Table E-1. Graduated Cylinder Mass and Volume Measurements ............................................ 43

Table E-2. Beaker and Graduated Cylinder Mass Measurements .............................................. 43

\section{LIST OF FIGURES}

Figure 1. Photographs of solid gel obtained during $\mathrm{NaOH}$ addition to simulant 1 ...................... 3

Figure 2. Photographs of tests 3 and 4 for each simulant following one day of settling............... 7

Figure 3. Powder XRD diffraction pattern of solids from Test 1-3

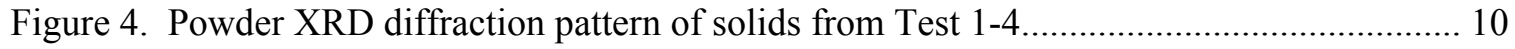

Figure 5. Powder XRD diffraction pattern of solids from Test 2-3 …...................................... 11

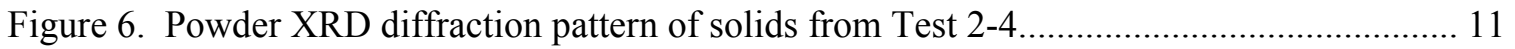

Figure 7. Powder XRD diffraction pattern of solids from Test 3-3 ......................................... 12

Figure 8. Powder XRD diffraction pattern of solids from Test 3-4

Figure 9. Settling rate of solids formed from the neutralizations of Simulant $1\left(0.5 \mathrm{M} \mathrm{HNO}_{3}\right.$,

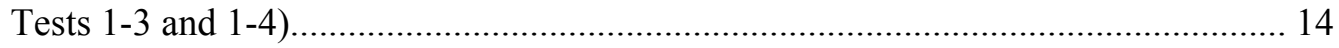

Figure 10. Settling rate of solids formed from the neutralizations of Simulant 2 (1.0 $\mathrm{M} \mathrm{HNO}_{3}$, Tests 2-3 and 2-4). 
Figure 11. Settling rate of solids formed from the neutralizations of Simulant $3\left(1.5 \mathrm{M} \mathrm{HNO}_{3}\right.$, Tests 3-3 and 3-4).

Figure 12. Number percentage particle size distributions for fully neutralized solutions (1.2 M free hydroxide)......

Figure 13. Volume percentage particle size distributions for fully neutralized solutions (1.2 M free hydroxide).

Figure 14. TGA results for centrifuged solids from the three U/Gd solutions neutralized to the last two endpoints ( $0.8 \mathrm{M}$ and $1.2 \mathrm{M}$ free hydroxide)

Figure 15. Safe amount of $\mathrm{Gd}$ needed for differing $\mathrm{H}: \mathrm{Pu}$ molar ratios (reproduced from ref. 10).

Figure C-1. a) SEM image of solids from Test 1-1. b,c,d) EDS spectra of spots 3, 4, and 5, respectively.

Figure C-2. a) SEM image of solids from Test 1-2. b,c,d) EDS spectra of spots 3, 4, and 5, respectively.

Figure C-3. a,b) SEM images of solids from Test 1-3. c,d,e) EDS spectra of spots 1, 3, and 4, respectively....

Figure C-4. a,b) SEM images of solids from Test 1-4. c,d,e) EDS spectra of spots 2, 3, and 4, respectively.

Figure C-5. a,b) SEM images of solids from Test 2-1. c) EDS spectra from raster scan. Inset shows expanded region focusing on U and Gd peaks. d,e) EDS spectra of spots 1 and2, respectively.

Figure C-6. a) SEM image of solids from Test 2-2. b,c,d) EDS spectra of spots 1, 2, and 3, respectively.

Figure C-7. a,b) SEM images of solids from Test 2-3. c,d,e) EDS spectra of spots 1, 2, and 3, respectively.

Figure C-8. a) SEM image of solids from Test 2-4. b,c) EDS spectra of spots 1 and 3, respectively.

Figure C-9. a,b) SEM images of solids from Test 3-1. c,d,e) EDS spectra of spots 1, 3, and 7, respectively.

Figure C-10. a,b) SEM images of solids from Test 3-2. c,d,e) EDS spectra of spots 1, 2, and 3, respectively

Figure C-11. a,b) SEM images of solids from Test 3-3. c,d,e) EDS spectra of spots 2, 3, and 4, respectively

Figure C-12. a,b) SEM images of solids from Test 3-4. c,d,e) EDS spectra of spots 1, 2, and 3, respectively..... 


\section{LIST OF ABBREVIATIONS}

$\begin{array}{ll}\text { EDS } & \text { energy dispersive spectroscopy } \\ \text { HLW } & \text { High Level Waste } \\ \text { ICP-ES } & \text { inductively coupled plasma - emission spectroscopy } \\ \text { SEM } & \text { scanning electron microscopy } \\ \text { SRNL } & \text { Savannah River National Laboratory } \\ \text { SRS } & \text { Savannah River Site } \\ \text { TGA-MS } & \text { thermogravimetric analysis - mass spectrometry } \\ \text { UNF } & \text { used nuclear fuel } \\ \text { XRD } & \text { X-ray diffraction }\end{array}$




\subsection{Introduction}

H-Canyon will begin dissolving High Aluminum - Low Uranium (High Al/Low U) Used Nuclear Fuel (UNF) following approval by DOE which is anticipated in CY2011. High A1/Low U UNF is an aluminum/enriched uranium alloy with small quantities of uranium relative to aluminum. The maximum enrichment level expected is $93 \%{ }^{235} \mathrm{U}$. The High $\mathrm{Al} / \mathrm{Low} \mathrm{U}$ UNF will be dissolved in H-Canyon in a nitric acid/mercury/gadolinium solution. The resulting solution will then be neutralized and transferred to Tank $39 \mathrm{H}$ in the Tank Farm. Gadolinium (Gd) is added as a neutron poison, and is very effective at capturing thermal neutrons; however it is less effective in capturing fast neutrons. Therefore, it is important that the fissile material, which is expected to precipitate upon neutralization, is always associated with enough hydrogen, in the form of water, to thermalize the neutrons.

Previous studies have demonstrated the feasibility of adding $\mathrm{Gd}$ as a neutron poison and neutralizing to $1.2 \mathrm{M}$ free hydroxide for solutions containing only $\mathrm{Pu}, 3: 1$ mixtures (by mass) of slightly enriched $\mathrm{U}(0.8 \%)$ and $\mathrm{Pu}$, solutions with a $4.3: 1 \mathrm{U}: \mathrm{Pu}$ mass ratio containing $\mathrm{U}$ with an enrichment level of $30 \%$, and with $U$ only solutions. ${ }^{1-3}$ These solutions contained little to no aluminum, with the highest concentration being $0.006 \mathrm{M}$. The expected $\mathrm{Al}$ concentration in the High $\mathrm{Al} /$ Low U UNF solutions is $1.5-2.0 \mathrm{M}$.

To confirm that the high Al/low U UNF solution generated during dissolution in H-Canyon can be poisoned with Gd, neutralized and discarded to the SRS HLW system without nuclear criticality safety concerns, solutions were prepared with the expected composition of the $\mathrm{H}$ Canyon solutions and neutralized. Neutralizations were performed using $50 \mathrm{wt} \%$ sodium hydroxide $(\mathrm{NaOH})$ solution. In this report neutralization refers to the $\mathrm{H}$-Canyon process of adding sufficient sodium hydroxide to bring the free hydroxide concentration to $1.2 \mathrm{M}$. The study aimed to measure the mass ratio of $U$ to $G d$ at four points during the neutralization, up to 1.2 $\mathrm{M}$ free hydroxide. The molar ratios of $\mathrm{H}$ to $\mathrm{U}$ were estimated from the amount of water associated with the solids produced during neutralization, after gravity settling and in the centrifuged solids. The particle size distribution of the precipitated solids from the fully neutralized solution was also measured.

This work was performed at the request of H-Canyon Engineering ${ }^{4}$ and was controlled by a Task Technical and Quality Assurance Plan (TTQAP). ${ }^{5}$

\subsection{Experimental Procedure}

\subsection{Simulant Solution Preparation}

The expected final concentrations after dissolution of the high Al/low U UNF were provided by $\mathrm{H}$-Canyon engineering to be $0.5-1.5 \mathrm{M}$ nitric acid $\left(\mathrm{HNO}_{3}\right), 0.002 \mathrm{M}$ mercury $(\mathrm{Hg}), 0.5-1.5 \mathrm{~g} / \mathrm{L}$ $\mathrm{U}, 1.5-2 \mathrm{M}$ aluminum (Al), and $0.58-1.7 \mathrm{~g} / \mathrm{L}$ gadolinium $(\mathrm{Gd})$. Three simulant solutions were prepared using the maximum values for $\mathrm{Al}, \mathrm{U}$, and $\mathrm{Gd}$ in three different nitric acid concentrations $0.5 \mathrm{M}, 1.0 \mathrm{M}$, and $1.5 \mathrm{M} \mathrm{HNO}_{3}$. The maximum $\mathrm{Al}$ concentration was chosen to more easily see the effect on Gd when the Al passes through a gelatinous phase. As the acidic solution is neutralized the $\mathrm{Al}$ will precipitate forming a gelatinous phase, and then as addition hydroxide is added the $\mathrm{Al}$ will redissolve as $\mathrm{Al}(\mathrm{OH})_{4}^{-}$. The maximum $\mathrm{U}$ concentration was selected because the study of $U$ and $\mathrm{Gd}$ precipitation is the focus of these experiments and at a lower $U$ concentration there would be less precipitation of $\mathrm{U}$, therefore the interaction between $\mathrm{Gd}$ and $\mathrm{U}$ would be harder to study. The simulants were prepared by dissolving reagent grade aluminum 
nitrate nonahydrate $\left(\mathrm{Al}\left(\mathrm{NO}_{3}\right)_{3} \cdot 9 \mathrm{H}_{2} \mathrm{O}\right)$, gadolinium nitrate hexahydrate $\left(\mathrm{Gd}\left(\mathrm{NO}_{3}\right)_{3} \cdot 6 \mathrm{H}_{2} \mathrm{O}\right)$, mercury (II) nitrate monohydrate $\left(\mathrm{Hg}\left(\mathrm{NO}_{3}\right)_{2} \bullet \mathrm{H}_{2} \mathrm{O}\right)$, and depleted uranyl nitrate hexahydrate $\left(\mathrm{UO}_{2}\left(\mathrm{NO}_{3}\right)_{2} \cdot 6 \mathrm{H}_{2} \mathrm{O}\right)$ in either $0.5,1.0$, or $1.5 \mathrm{M} \mathrm{HNO}_{3}$. The compositions of the simulants are provided in Table 2-1. An additional non-radioactive simulant containing only Gd and Al was also prepared in $0.5 \mathrm{M} \mathrm{HNO}_{3}$. This simulant was used for testing to track the precipitation of $\mathrm{Gd}$ over the $\mathrm{pH}$ range seen during the neutralizations.

Table 2-1. Composition of Simulant Solutions

\begin{tabular}{|c|c|c|c|c|c|}
\hline Simulant & {$\left[\mathrm{HNO}_{3}\right] \mathbf{( M )}$} & {$[\mathbf{A l}] \mathbf{( M )}$} & {$[\mathbf{G d}] \mathbf{( g / L )}$} & {$[\mathbf{U}] \mathbf{( g / L )}$} & {$[\mathbf{H g}] \mathbf{( M )}$} \\
\hline 1 & 0.5 & 2.0 & 1.725 & 1.5 & 0.002 \\
\hline 2 & 1.0 & 2.0 & 1.725 & 1.5 & 0.002 \\
\hline 3 & 1.5 & 2.0 & 1.725 & 1.5 & 0.002 \\
\hline 4 & 0.5 & 2.0 & 1.725 & 0.0 & 0.0 \\
\hline
\end{tabular}

\subsection{Precipitation and Sampling}

Precipitation tests were performed using four $25-50 \mathrm{~mL}$ aliquots of each simulant. Each aliquot was used for testing a different endpoint. The four planned target endpoints were 1) when solids first precipitate, expected to be at a $\mathrm{pH}$ of about $4.5 ; 2$ ) at $\mathrm{pH} 7 ; 3$ ) at $0.8 \mathrm{M}$ free hydroxide; and 4) at $1.2 \mathrm{M}$ free hydroxide. However, experimentally it was found the first two endpoints were difficult to obtain. Solids began to precipitate immediately upon the addition of $\mathrm{NaOH}$, and upon nearing a $\mathrm{pH}$ of 4.5 an almost completely solid phase is obtained due to the Al precipitation, making stirring and measuring $\mathrm{pH}$ impossible. See Figure 1 for a photograph of this solid phase formation. As more $\mathrm{NaOH}$ is added, the Al begins to redissolve, eventually making stirring possible. The $\mathrm{pH}$ increases rapidly at this point, making an endpoint of $\mathrm{pH} 7$ difficult to obtain. Due to these constraints the first two target endpoints were changed to 1) the point just before the solid gel is formed, but where there is still liquid present to sample and 2) the point where a solid phase is obtained. 25 or $50 \mathrm{~mL}$ of each simulant were measured using a graduated cylinder and transferred to 100 or $250-\mathrm{mL}$ beakers. The smaller aliquots were used for the first two endpoints, while the larger aliquots were used for the latter two. The aliquots were stirred at $500 \mathrm{rpm}$ with a magnetic stir bar and neutralized to the desired endpoint by the drop-wise addition of a $50 \mathrm{wt} \%$ $\mathrm{NaOH}$ solution ensuring that the temperature of the solutions did not exceed $50{ }^{\circ} \mathrm{C}$. The volume of the $\mathrm{NaOH}$ solution added was determined by both the burette readings and by mass (Table 2-2).

Table 2-2. Volume of NaOH Added for Each Test

\begin{tabular}{|c|c|c|c|c|c|c||}
\hline \hline Test & Simulant & $\begin{array}{c}\text { Volume of } \\
\text { Solution } \\
\text { Neutralized (mL) }\end{array}$ & $\begin{array}{c}\text { Neutralization } \\
\text { Endpoint }\end{array}$ & $\begin{array}{c}\text { Volume } \\
\mathbf{5 0} \text { wt \% } \\
\text { NaOH Added } \\
(\mathbf{m L})^{\mathbf{a}}\end{array}$ & $\begin{array}{c}\text { Mass 50 wt \% } \\
\text { NaOH Added } \\
\text { (g) }\end{array}$ & $\begin{array}{c}\text { Volume } \\
\mathbf{5 0} \text { wt \% } \\
\text { NaOH Added } \\
\mathbf{( m L}^{\mathbf{b}}\end{array}$ \\
\hline $1-1$ & 1 & 25 & $\mathrm{pH} 4$ & 6.5 & 8.653 & 5.7 \\
\hline $1-2$ & 1 & 25 & solid gel & 7.2 & 10.349 & 6.8 \\
\hline $1-3$ & 1 & 50 & $0.8 \mathrm{M}$ free $\mathrm{OH}^{-}$ & 25.6 & 36.518 & 24.0 \\
\hline $1-4$ & 1 & 50 & $1.2 \mathrm{M}$ free $\mathrm{OH}^{-}$ & 27.4 & 39.074 & 25.7 \\
\hline $2-1$ & 2 & 25 & $\mathrm{pH} \mathrm{3.5}$ & 5.7 & 7.929 & 5.2 \\
\hline $2-2$ & 2 & 25 & solid gel & 7.4 & 10.695 & 7.0 \\
\hline $2-3$ & 2 & 50 & $0.8 \mathrm{M}$ free $\mathrm{OH}^{-}$ & 26.9 & 38.256 & 25.2 \\
\hline $2-4$ & 2 & 50 & $1.2 \mathrm{M}$ free $\mathrm{OH}^{-}$ & 28.7 & 40.710 & 26.8 \\
\hline $3-1$ & 3 & 25 & $\mathrm{pH} 3.5$ & 7.0 & 9.808 & 6.5 \\
\hline $3-2$ & 3 & 25 & solid gel & 7.7 & 11.141 & 7.3 \\
\hline $3-3$ & 3 & 50 & $0.8 \mathrm{M}$ free $\mathrm{OH}^{-}$ & 28.3 & 40.661 & 26.8 \\
\hline $3-4$ & 3 & 50 & $1.2 \mathrm{M}$ free $\mathrm{OH}^{-}$ & 30.1 & 43.580 & 28.7 \\
\hline
\end{tabular}

a) Based on burette reading.

b) Calculated from mass using a density of $1.52 \mathrm{~g} / \mathrm{mL}$. 

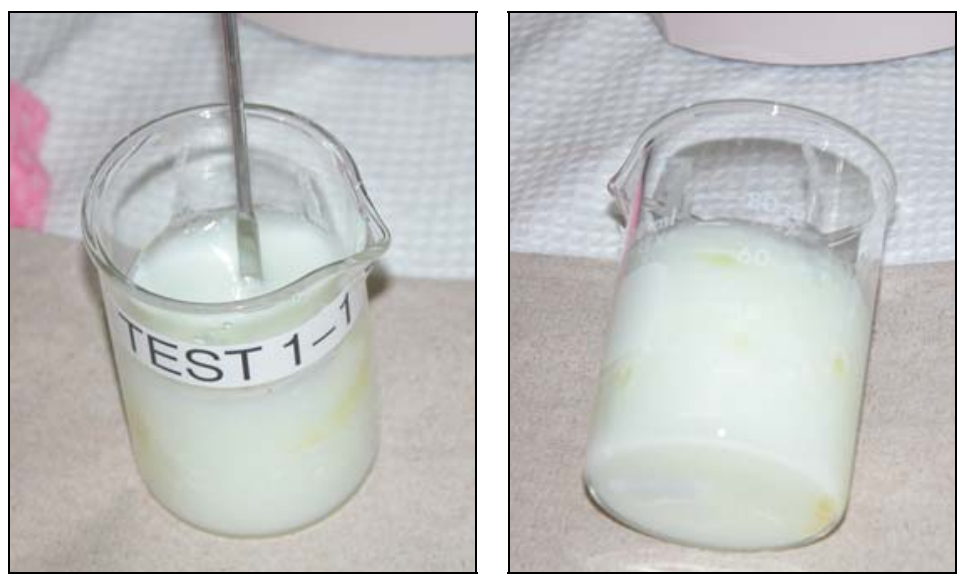

Figure 1. Photographs of solid gel obtained during $\mathrm{NaOH}$ addition to simulant 1.

Once the desired endpoint was reached, the beakers were covered with Parafilm $\mathrm{M}^{\mathrm{TM}}$ and the mixtures were stirred for 1-2 hours prior to sampling, with the exception of the second endpoint for each simulant, which was a solid and could not be stirred. The $\mathrm{pH}$ of the first endpoint was measured with a $\mathrm{pH}$ test strip, and the result is listed in Table 2-2 as the endpoint.

For Tests 1, 3, and 4 with each simulant, two $1.5-\mathrm{mL}$ aliquots of the precipitate slurry were removed from each beaker, while stirring, and transferred into two $1.5-\mathrm{mL}$ conical centrifuge tubes. The tubes were then centrifuged for 5 minutes to separate the solids. The supernate from each tube was decanted, and a 1-mL aliquot of the supernate was diluted to a total volume of $10 \mathrm{~mL}$ with distilled water. This sample was then submitted for inductively coupled plasma emission spectroscopy (ICP-ES) analysis to determine the concentrations of $\mathrm{Al}, \mathrm{U}$, and $\mathrm{Gd}$. A sample of the solids from each test was dissolved in $1 \mathrm{~mL}$ of $8 \mathrm{M} \mathrm{HNO}_{3}$. After dissolving, this sample was diluted with $9 \mathrm{~mL}$ of distilled water. These samples were also submitted for ICP-ES analysis to determine the $\mathrm{Al}, \mathrm{U}$, and $\mathrm{Gd}$ content. For test 2 with each simulant, samples of the solid were transferred to two $1.5-\mathrm{mL}$ centrifuge tubes using a spatula. These samples were centrifuged for 10 minutes; however, no liquid separated. Samples of the solid were then dissolved in $1 \mathrm{~mL}$ of $8 \mathrm{M} \mathrm{HNO}_{3}$. After dissolving, these samples were diluted by adding $9 \mathrm{~mL}$ of distilled water, and were submitted for ICP-ES analysis. Additional samples of the solids from each test were submitted for X-ray diffraction (XRD) and scanning electron microscopy (SEM) analyses.

To track the precipitation of $\mathrm{Gd}$ over the $\mathrm{pH}$ range seen during the neutralizations, an additional test was completed using a non-radioactive simulant containing only Al and Gd (Simulant 4). For this test, $50 \mathrm{~mL}$ of simulant 4 was measured using a graduated cylinder, and was transferred to a $150-\mathrm{mL}$ beaker. The solution was stirred at $500 \mathrm{rpm}$ with a magnetic stir bar and $50 \mathrm{wt} \% \mathrm{NaOH}$ was added drop-wise while ensuring that the temperature of the solution did not exceed $50{ }^{\circ} \mathrm{C}$. Samples were removed periodically during the addition. When sampling the $\mathrm{pH}$ was measured, and the volume of $\mathrm{NaOH}$ that had been added was determined from the burette reading. For most samples a $1.5-\mathrm{mL}$ aliquot was removed from the beaker while stirring and was transferred to a $1.5-\mathrm{mL}$ centrifuge tube. For samples taken that had a large amount of solids, a $3.0-\mathrm{mL}$ aliquot was removed and transferred into two $1.5-\mathrm{mL}$ centrifuge tubes, to ensure enough supernate would be obtained to sample. The samples were then centrifuged for 5 minutes. The supernate from each tube was decanted, and a $1-\mathrm{mL}$ aliquot of the supernate was diluted to a total volume of 10 $\mathrm{mL}$ with distilled water. For some samples less than $1 \mathrm{~mL}$ of supernate was isolated, and a 
smaller aliquot was diluted for analysis. These different dilution factors were taken into account when analyzing the results. These samples were then submitted for ICP-ES analysis to determine the concentrations of $\mathrm{Al}$ and $\mathrm{Gd}$. A sample of the solids from each test was also dissolved in either nitric or sulfuric acid, or a combination of both. Some solid samples were not successfully dissolved, and were therefore not analyzed. After dissolving, the samples were also diluted with distilled water, and were submitted for ICP-ES analysis. Table 2-3 provides a summary of samples removed during this test.

Table 2-3. Summary of Samples Removed During Cold Test

\begin{tabular}{||c|c|c|c||}
\hline Sample \# & $\mathbf{p H}$ & $\begin{array}{c}\text { Volume 50 wt \% NaOH Added } \\
(\mathbf{m L})^{\mathbf{a}}\end{array}$ & Volume of Sample Removed (mL) \\
\hline 1 & $<1$ & 2.8 & 1.5 \\
\hline 2 & 1.5 & 4.6 & 1.5 \\
\hline 3 & 2.5 & 6.7 & 1.5 \\
\hline 4 & 3 & 8.3 & 1.5 \\
\hline 5 & 3.5 & 9.7 & 1.5 \\
\hline 6 & 3.5 & $\mathrm{NR}^{\mathrm{b}}$ & 1.5 \\
\hline 7 & 4 & 12.2 & 3.0 \\
\hline 8 & $\mathrm{n} / \mathrm{a}-\mathrm{solid}$ & 13.2 & 3.0 \\
\hline 9 & 13 & 15.6 & 1.5 \\
\hline 10 & 14 & 18.3 & 1.5 \\
\hline 11 & $>14$ & 20.9 & 1.5 \\
\hline 12 & $>14$ & 24.4 & 1.5 \\
\hline
\end{tabular}

a) Based on burette reading, total amount added (cumulative).

b) $\mathrm{NR}=$ not recorded, the burette reading was not recorded at this sampling event.

\subsection{Density}

Tests 1 and 2 for each simulant contained insufficient supernate to complete the density measurements. The densities of the supernate and precipitate slurry from neutralizations 3 and 4 for each simulant were determined gravimetrically. After settling for 24 hours, a 5-mL aliquot of the supernate was transferred to a beaker and the mass was determined by difference. The supernate was transferred back to the original beaker. The contents of the beaker were then stirred and a 5-mL aliquot of the supernate and solids was removed. The supernate and solids were transferred to a beaker and the mass was determined by difference. The density of the supernate and settled solids were also determined during the measurement of $\mathrm{H}$ ratios in settled solids (see section below).

\subsection{Settling Experiments}

The settling times for the solids precipitated during neutralizations 3 and 4 for each simulant were measured using a $25-\mathrm{mL}$ graduated cylinder. Prior to the measurement, each neutralized solution was stirred until well mixed. An approximately $25-\mathrm{mL}$ aliquot was then transferred to the graduated cylinder. The solids were allowed to settle and the volume corresponding to the top of the solids in the graduated cylinder was recorded as a function of time.

\subsection{Particle Size Analysis}

The particle size distributions of the solids produced during the neutralizations to $1.2 \mathrm{M}$ free hydroxide were measured using a Leeds and Northrup Microtrac II particle size analyzer. Diluent was prepared for each sample to closely match the ionic strength of precipitation supernate. The diluent was prepared by neutralizing a solution containing the appropriate amount of $\mathrm{HNO}_{3}(0.5$, 1.0 , or $1.5 \mathrm{M}$ ) plus enough additional $\mathrm{HNO}_{3}$ to account for the nitrate associated with the $\mathrm{U}, \mathrm{Gd}$, $\mathrm{Hg}$, and $\mathrm{Al}$ in each solution. The $\mathrm{HNO}_{3}$ solution was neutralized with $50 \mathrm{wt} \% \mathrm{NaOH}$ to $1.2 \mathrm{M}$ 
free hydroxide. The analysis was performed by adding the precipitate slurry to the diluent until the concentration of particles was sufficient to perform the measurement.

\section{6 $\underline{\mathrm{H}: \mathrm{U} \text { Ratios }}$}

$\mathrm{H}$ to $\mathrm{U}$ ratios were calculated by determining the amount of water associated with the solids for two different accident scenarios. The first scenario represents agitator failure, and in this case the amount of water associated with the settled solids was determined. The second scenario represents the solids drying out in an unagitated pump box. To calculate the $\mathrm{H}$ to $\mathrm{U}$ ratio for this scenario, the amount of water associated with the centrifuged solids was determined. The procedure used to measure the water content of the settled solids is given in Appendix A. Once the water content was known, the $\mathrm{H}$ ratios were calculated from the $\mathrm{U}$ analyses for the solids and the known stoichiometry.

The amount of water present in the centrifuged solids from the neutralized solutions was determined by thermogravimetric analysis. A sample from each solution was prepared by transferring $1.5 \mathrm{~mL}$ of the well mixed precipitate slurry to a conical centrifuge tube. The samples were centrifuged for 5 minutes and the supernate removed. The solids were transferred from the centrifuge tube to a combined thermogravimetric analyzer-mass spectrometer (TGA-MS). Samples were loaded into alumina crucibles which had been dried at $1000{ }^{\circ} \mathrm{C}$ prior to use. The samples were then heated at $10{ }^{\circ} \mathrm{C} / \mathrm{min}$ up to $750{ }^{\circ} \mathrm{C}$. Before and after the analyses, gypsum $\left(\mathrm{CaSO}_{4} \cdot 2 \mathrm{H}_{2} \mathrm{O}\right)$ standards were heated in the TGA to confirm that waters of hydration were removed between nominally $100-300{ }^{\circ} \mathrm{C}$, that the mass loss due to waters of hydration was within $2 \%$ of their theoretical mass, and that the MS peak areas for moisture increased linearly with moisture mass. Inspection of the TGA-MS results showed that moisture release could be quantified by the TGA mass loss to $300{ }^{\circ} \mathrm{C}$. Above that temperature, moisture was not released but other impurities were volatilized. The high moisture levels in these samples were generally outside the range of calibration for the MS. Nevertheless, estimates of moisture using MS peak areas matched the TGA moisture values within $10 \%$. The water associated with the centrifuged solids was calculated using the difference in the initial mass and the mass of the sample at $300{ }^{\circ} \mathrm{C}$. The $\mathrm{H}$ to $\mathrm{U}$ ratios were subsequently calculated using the water content of the solids, the $\mathrm{U}$ and Gd analyses for the solids, and the stoichiometry of compounds assumed for the precipitated solids.

\subsection{Results and Discussion}

\subsection{Experimental}

This work was performed to support the use of Gd as a neutron poison for neutralization of High Al/Low U UNF solutions and subsequent disposal of those solutions to the SRS HLW system. Gadolinium is an effective neutron poison for the H-Canyon process as long as enough Gd is uniformly distributed within the fissile material, the particles are small, and the neutrons being absorbed are thermalized. For neutralized solids, this means uniform solids must be precipitated. The size of the precipitated solids needs to be less than 100 microns so Gd self-shielding is minimized. Finally, enough $\mathrm{H}$ in the form of water is required to thermalize the neutrons.

The H:U ratio needed for the safe neutralization of more than a fissile mass of $U$ depends both on the Gd:U ratio and the H:U ratio. Both ratios have been measured for three scenarios. The first is for partial and full neutralization where the neutralization tank is agitated throughout the neutralization process. In this case, plenty of water is present to thermalize the neutrons so only the Gd:U ratio is important. The second scenario, which corresponds to losing agitation in the tank during neutralization followed by settling of the solids, requires both $\mathrm{H}: \mathrm{U}$ and $\mathrm{Gd}: \mathrm{U}$ ratios in 
the settled solids to attain a certain level. The final scenario, corresponds to the solids drying out in an unagitated pump box. Once again H:U and Gd:U ratios in the packed solids are important. For the last two scenarios, sufficient Gd was used in the experiments so that if the solution was neutralized, only the thermalization of the neutrons or the $\mathrm{H}: \mathrm{U}$ ratio was important. The limiting $\mathrm{H}: \mathrm{U}$ ratio must be determined by a nuclear criticality safety evaluation; however, previous $\mathrm{H}$ :fissile ratios will be used here for comparison as they are expected to be greater than those for ${ }^{235} \mathrm{U}$ due to its lower mass deficit than ${ }^{239} \mathrm{Pu}$ and less energetic neutron spectrum.

\subsection{Visual Observations}

The U/Gd solutions were pale yellow in color. The yellow color is characteristic of uranyl nitrate solutions. In all tests, precipitation of a white solid was observed immediately upon $\mathrm{NaOH}$ addition. It has been reported that the presence of a local hydroxide concentration appreciably larger than the overall concentration can lead to the formation of an $\mathrm{Al}$ precipitate that is reluctant to redissolve, even though it is unstable. ${ }^{6}$ The formation of these high local hydroxide concentration areas as $\mathrm{NaOH}$ drops into the acidic solution in combination with the fact that the $\mathrm{Al}$ concentration in these solutions is near the solubility limit likely caused this early formation of a precipitate. At $20^{\circ} \mathrm{C}$, the solubility of $\mathrm{Al}\left(\mathrm{NO}_{3}\right)_{3}$ in $0.5 \mathrm{M}$ nitric acid is approximately $2.4 \mathrm{M}$, and decreases as the concentration of nitric acid increases. ${ }^{7}$ In a $1.5 \mathrm{M} \mathrm{HNO}_{3}$ solution, the $\mathrm{Al}\left(\mathrm{NO}_{3}\right)_{3}$ solubility is approximately $2.2 \mathrm{M}^{7}$

As more $\mathrm{NaOH}$ was added, precipitation of solids continued up to a point where an almost completely solid matrix was formed. This point was reached shortly after reaching a $\mathrm{pH}$ of 4 .

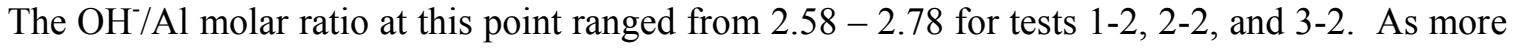
$\mathrm{NaOH}$ was added, some of the precipitated $\mathrm{Al}$ redissolved, as expected. The formation of this nearly solid phase is not expected to be an issue during Canyon operations, as the $\mathrm{NaOH}$ will be added at a much more rapid rate, quickly passing through this phase and redissolving the precipitated Al. The neutralized solutions at $0.8 \mathrm{M}$ and $1.2 \mathrm{M}$ free hydroxide for each simulant are shown in Figure 2, following one day of settling. The mixtures obtained at the first two endpoints were either a solid gel or contained so little liquid that settling was not observed. The solids from the later two endpoints for each simulant were easily resuspended.

\subsection{Neutralization Tests}

The Gd:U ratios obtained from the neutralization experiments are shown in Table 3-1. The ratios were calculated from the ICP-ES analyses. Sample calculations are shown in Appendix B. The mass ratios reflect the fact that all of the $\mathrm{U}$ and $\mathrm{Gd}$ is expected to precipitate at full neutralization. All of the simulants have $U$ concentrations of $1.5 \mathrm{~g} / \mathrm{L}$ and $\mathrm{Gd}$ concentrations of $1.725 \mathrm{~g} / \mathrm{L}$. If all the $\mathrm{U}$ and $\mathrm{Gd}$ precipitated at full neutralization, the $\mathrm{Gd}: \mathrm{U}$ solids mass ratios would be 1.15 , which is what was found experimentally if the $(1 \sigma) 10 \%$ measurement uncertainty is taken into account. 

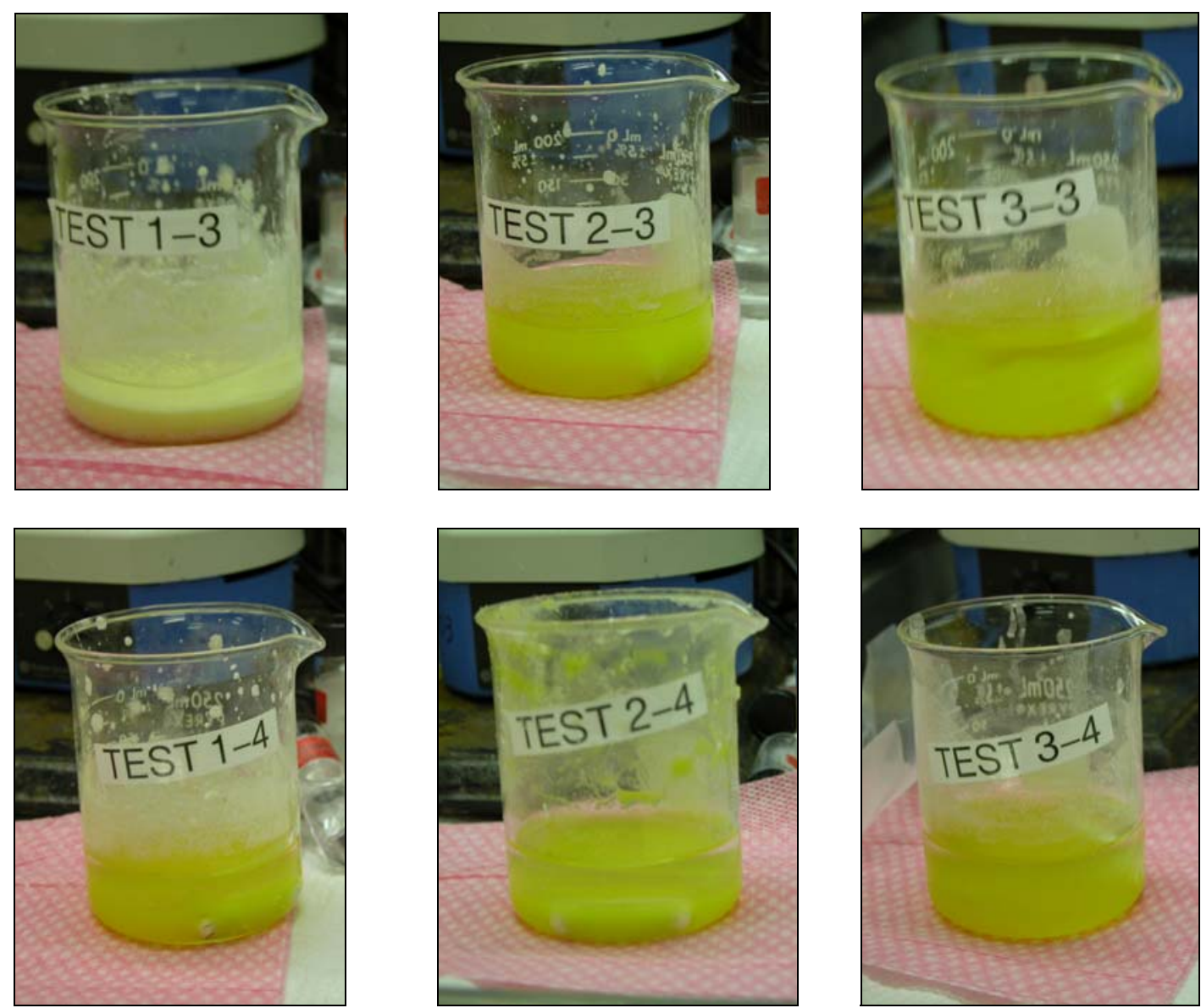

Figure 2. Photographs of tests 3 and 4 for each simulant following one day of settling.

Table 3-1. Gd:U Mass Ratios in the Neutralized Solutions

\begin{tabular}{||c|c|c|c|c||}
\hline Test & Simulant & Endpoint & $\begin{array}{c}\text { Supernate Gd:U Mass } \\
\text { Ratio }\end{array}$ & $\begin{array}{c}\text { Solids Gd:U Mass } \\
\text { Ratio }\end{array}$ \\
\hline $1-1$ & 1 & $\mathrm{pH} 4$ & 1.25 & 1.10 \\
\hline $1-2$ & 1 & solid phase & $\mathrm{n} / \mathrm{a}$ & 1.17 \\
\hline $1-3$ & 1 & $0.8{\mathrm{M} \text { free } \mathrm{OH}^{-}}^{-}$ & $>0.17^{\mathrm{a}}$ & 1.17 \\
\hline $1-4$ & 1 & $1.2 \mathrm{M}$ free $\mathrm{OH}^{-}$ & $>0.08^{\mathrm{a}}$ & 1.14 \\
\hline $2-1$ & 2 & $\mathrm{pH} \mathrm{3.5}$ & 1.21 & 1.04 \\
\hline $2-2$ & 2 & solid phase & $\mathrm{n} / \mathrm{a}$ & 1.16 \\
\hline $2-3$ & 2 & $0.8 \mathrm{M}$ free $\mathrm{OH}^{-}$ & $>0.07^{\mathrm{a}}$ & 1.16 \\
\hline $2-4$ & 2 & $1.2 \mathrm{M}$ free $\mathrm{OH}^{-}$ & $>0.13^{\mathrm{a}}$ & 1.12 \\
\hline $3-1$ & 3 & $\mathrm{pH} 3.5$ & 1.29 & 1.02 \\
\hline $3-2$ & 3 & solid phase & $\mathrm{n} / \mathrm{a}$ & 1.16 \\
\hline $3-3$ & 3 & $0.8 \mathrm{M}$ free $\mathrm{OH}^{-}$ & $>0.10^{\mathrm{a}}$ & 1.14 \\
\hline $3-4$ & 3 & $1.2 \mathrm{M}$ free $\mathrm{OH}^{-}$ & $>0.08^{\mathrm{a}}$ & 1.15 \\
\hline \hline
\end{tabular}

a) For these samples the U concentration was below the method detection limit, resulting in less than values being reported. These maximum concentrations were then used to calculate the ratios given in Table 3-1. 
The same data are presented in Table 3-2 as the percent precipitated when the initial solution is partially and fully neutralized. Sample calculations are also shown in Appendix B. As expected, nearly $100 \%$ of the $\mathrm{U}$ and Gd precipitate at full neutralization. Similar levels of precipitation were also seen at $0.8 \mathrm{M}$ free hydroxide. Less $\mathrm{U}$ and $\mathrm{Gd}$ precipitate at $\mathrm{pH} 3.5-4$. This same trend was seen in the previous work; however, larger percentages of $\mathrm{Gd}$ were found to precipitate in these solutions at $\mathrm{pH} 4$, compared to the previous work. ${ }^{1-3}$

Table 3-2. Percentage of Each Element Precipitated from Solution Upon Neutralization ${ }^{\mathrm{a}}$

\begin{tabular}{||c|c|c|c|c|c||}
\hline Test & Simulant & Endpoint & Gd & U & Al \\
\hline $1-1$ & 1 & $\mathrm{pH} 4$ & $13.1 \%$ & $20.0 \%$ & $36.7 \%$ \\
\hline $1-2$ & 1 & solid phase & $\mathrm{n} / \mathrm{a}$ & $\mathrm{n} / \mathrm{a}$ & $\mathrm{n} / \mathrm{a}$ \\
\hline $1-3$ & 1 & $0.8 \mathrm{M}$ free $\mathrm{OH}^{-}$ & $99.3 \%$ & $>95.5 \%{ }^{\mathrm{b}}$ & $19.9 \%$ \\
\hline $1-4$ & 1 & $1.2 \mathrm{M}$ free $\mathrm{OH}^{-}$ & $99.4 \%$ & $>90.8 \%^{\mathrm{b}}$ & $15.7 \%$ \\
\hline $2-1$ & 2 & $\mathrm{pH} 3.5$ & $15.3 \%$ & $19.6 \%$ & $33.6 \%$ \\
\hline $2-2$ & 2 & solid phase & $\mathrm{n} / \mathrm{a}$ & $\mathrm{n} / \mathrm{a}$ & $\mathrm{n} / \mathrm{a}$ \\
\hline $2-3$ & 2 & $0.8 \mathrm{M}$ free $\mathrm{OH}^{-}$ & $99.5 \%$ & $>90.9 \%$ & $26.8 \%$ \\
\hline $2-4$ & 2 & $1.2 \mathrm{M}$ free $\mathrm{OH}^{-}$ & $98.9 \%$ & $>90.7 \%$ & $13.7 \%$ \\
\hline $3-1$ & 3 & $\mathrm{pH} 3.5$ & $16.9 \%$ & $26.2 \%$ & $45.2 \%$ \\
\hline $3-2$ & 3 & solid phase & $\mathrm{n} / \mathrm{a}$ & $\mathrm{n} / \mathrm{a}$ & $\mathrm{n} / \mathrm{a}$ \\
\hline $3-3$ & 3 & $0.8 \mathrm{M}$ free $\mathrm{OH}^{-}$ & $99.2 \%$ & $>90.7^{\mathrm{b}}$ & $25.7 \%$ \\
\hline $3-4$ & 3 & $1.2 \mathrm{M}$ free $\mathrm{OH}^{-}$ & $99.3 \%$ & $>90.5^{\mathrm{b}}$ & $19.5 \%$ \\
\hline
\end{tabular}

a) Based on concentration measured in supernate, which has a $10 \%$ analytical uncertainty.

b) The U concentration in the supernate samples from these tests was below the method detection limit, so these values are minimum precipitation percentages.

The results from the non-radioactive testing with simulant 4 are shown in Table 3-3. A similar trend was seen in this experiment, where only a small amount of Gd precipitated at $\mathrm{pH}$ of 4 and below, but once passing through the solid phase nearly $100 \%$ of the Gd precipitates. The $\mathrm{Al}$ continually precipitates until reaching the point of maximum solids just past a $\mathrm{pH}$ value of 4 , and then begins to redissolve as $\mathrm{Al}(\mathrm{OH})_{4}{ }^{-}$as additional $\mathrm{NaOH}$ is added. ${ }^{8}$

Table 3-3. Percentage of Each Element Precipitated from Solution upon Neutralization of Simulant $4^{\mathrm{a}}$

\begin{tabular}{|c|c|c|c||}
\hline \hline Sample \# & $\mathbf{p H}$ & $\mathbf{A l}$ & $\mathbf{G d}$ \\
\hline 1 & $<1$ & $2.74 \%$ & $0.22 \%$ \\
\hline 2 & 1.5 & $13.9 \%$ & $7.49 \%$ \\
\hline 3 & 2.5 & $13.2 \%$ & $4.38 \%$ \\
\hline 4 & 3 & $22.2 \%$ & $8.93 \%$ \\
\hline 5 & 3.5 & $27.4 \%$ & $11.0 \%$ \\
\hline 6 & 3.5 & $36.0 \%$ & $18.6 \%$ \\
\hline 7 & 4 & $49.4 \%$ & $25.3 \%$ \\
\hline 8 & $\mathrm{n} / \mathrm{a}-$ solid & $99.0 \%$ & $98.3 \%$ \\
\hline 9 & 13 & $90.1 \%$ & $>99.4 \%{ }^{\mathrm{b}}$ \\
\hline 10 & 14 & $26.4 \%$ & $>99.5 \%{ }^{\mathrm{b}}$ \\
\hline 11 & $>14$ & $13.8 \%$ & $98.4 \%$ \\
\hline 12 & $>14$ & $8.23 \%$ & $98.6 \%$ \\
\hline \hline
\end{tabular}

a) Based on concentration measured in supernate.

b) The Gd concentration in the supernate samples from these tests was below the method detection limit, so these values are minimum precipitation percentages. 


\subsection{SEM and XRD Analysis}

Scanning electron micrographs and energy dispersive spectra (EDS) were obtained for the solids from each neutralization with a LEO-440 electron microscope. Representative micrographs for the solids are shown in Appendix C.

EDS characterization of the solids from the first two neutralization endpoints with Simulant 1 detected no U or Gd in the solids. Solids from Test 1-1 appeared largely crystalline, and EDS identified them as $\mathrm{Na}$ and $\mathrm{Al}$ containing material, likely $\mathrm{NaNO}_{3}$ and $\mathrm{Al}(\mathrm{OH})_{3}$. Solids from Test 1-2 appeared both amorphous and crystalline, and the EDS spectra were similar to the solids from Test 1-1. In the latter two neutralization endpoints ( 0.8 and $1.2 \mathrm{M}$ free hydroxide) with Simulant 1 , small amounts of $\mathrm{U}$ and $\mathrm{Gd}$ were detected in the mainly $\mathrm{Na}$ and $\mathrm{Al}$ containing solids. For Test 1-3 there were some areas of brighter solids located on some larger agglomerates, and EDS relative peak intensities indicated that these solids contained larger amounts of $\mathrm{Gd}$ and $\mathrm{U}$ compared to the bulk solids (Fig. C-3 b, e). In Test 1-4, the solids appeared mainly amorphous and were found to be $\mathrm{Na}$ and $\mathrm{Al}$ rich, with small amounts of $\mathrm{Gd}$ and $\mathrm{U}$. There was also some large plate-like crystalline material, likely $\mathrm{NaNO}_{3}$. A few bright areas were also identified as primarily $\mathrm{Hg}$ (Fig. C-4 b, e).

Similar results were seen for the solids from the neutralizations of Simulants 2 and 3. For Test 21, a large area raster scan indicated the solids were primarily $\mathrm{Na}$ and $\mathrm{Al}$ phases with small amounts of $\mathrm{Gd}$ and $\mathrm{U}$ detected. Again, larger crystalline $\mathrm{Na}$ rich phases were seen, likely $\mathrm{NaNO}_{3}$. The smaller, more amorphous looking particles were found to be an $\mathrm{Al}$ rich phase, likely $\mathrm{Al}(\mathrm{OH})_{3}$, with small amounts of $U$ and Gd. Similar results were seen for Test 2-2, except that $U$ and Gd were not detected in the large area raster scan. For Test 2-3, the solids were again identified as mainly $\mathrm{Na}$ and $\mathrm{Al}$ phases, with small amounts of Gd and $\mathrm{U}$. A few small particles were found to contain higher amounts of $\mathrm{U}$ compared to the bulk solids (Fig. C-7 a, c). There were also a few bright spots shown to be primarily $\mathrm{Hg}$ with smaller amounts of $\mathrm{U}, \mathrm{Gd}$, and $\mathrm{Na} / \mathrm{Al}$ phases (Fig. C$7 \mathrm{~b}$, e). There were also crystalline particles, likely $\mathrm{NaNO}_{3}$, observed. In Test 2-4, the solids were again found to be primarily $\mathrm{Na}$ and $\mathrm{Al}$ phases, with small amounts of $\mathrm{Gd}$ and $\mathrm{U}$. A small lighter area was shown to contain higher amounts of $\mathrm{Gd}$ and $\mathrm{U}$ compared to the bulk solids (Fig. C-8, a, c).

In all of the solids from the neutralization of Simulant $3, \mathrm{NaNO}_{3}$ crystalline particles were observed. The bulk solids in all four of the neutralizations were found to be mainly $\mathrm{Al}$ and $\mathrm{Na}$ phases with small amounts of Gd and U. In Tests 3-1 and 3-3, bright spots composed primarily of $\mathrm{Hg}$ were observed (Fig. C-9 a, c and C-11 b, e). Tests 3-2 and 3-4 contained some brighter amorphous looking solids which were found to be higher in $\mathrm{U}$ and $\mathrm{Gd}$ compared to the bulk solids (C-10 a, c and C-12 b, e).

X-ray diffraction results (Figures 3-8) were obtained for the solids precipitated at the two latter neutralization endpoints $(0.8 \mathrm{M}$ and $1.2 \mathrm{M}$ free hydroxide) for each simulant. All samples had characteristic X-ray lines of $\mathrm{NaNO}_{3}$. The solids from the neutralizations of Simulants 1 and 2 also contained sodium carbonate $\left(\mathrm{Na}_{2} \mathrm{CO}_{3}\right)$. The presence of $\mathrm{Na}_{2} \mathrm{CO}_{3}$ is due to the reaction of $\mathrm{NaOH}$ with carbon dioxide $\left(\mathrm{CO}_{2}\right)$ in the atmosphere (equation 1). In addition, $\mathrm{Al}(\mathrm{OH})_{3}$ was detected in the solids from Test 1-3. No Gd or U phases were detected in any of the solids. This could be due to either the fact that the solids were amorphous, or that the concentration of the Gd and $U$ containing solids was too low for detection. Based on these results, the solids from the first two endpoints ( $\mathrm{pH} 3.5-4$ and solid gel phase) were not analyzed, as even lower Gd and U concentrations are expected in these solids. 


$$
2 \mathrm{NaOH}+\mathrm{CO}_{2} \rightarrow \mathrm{Na}_{2} \mathrm{CO}_{3}+\mathrm{H}_{2} \mathrm{O}
$$

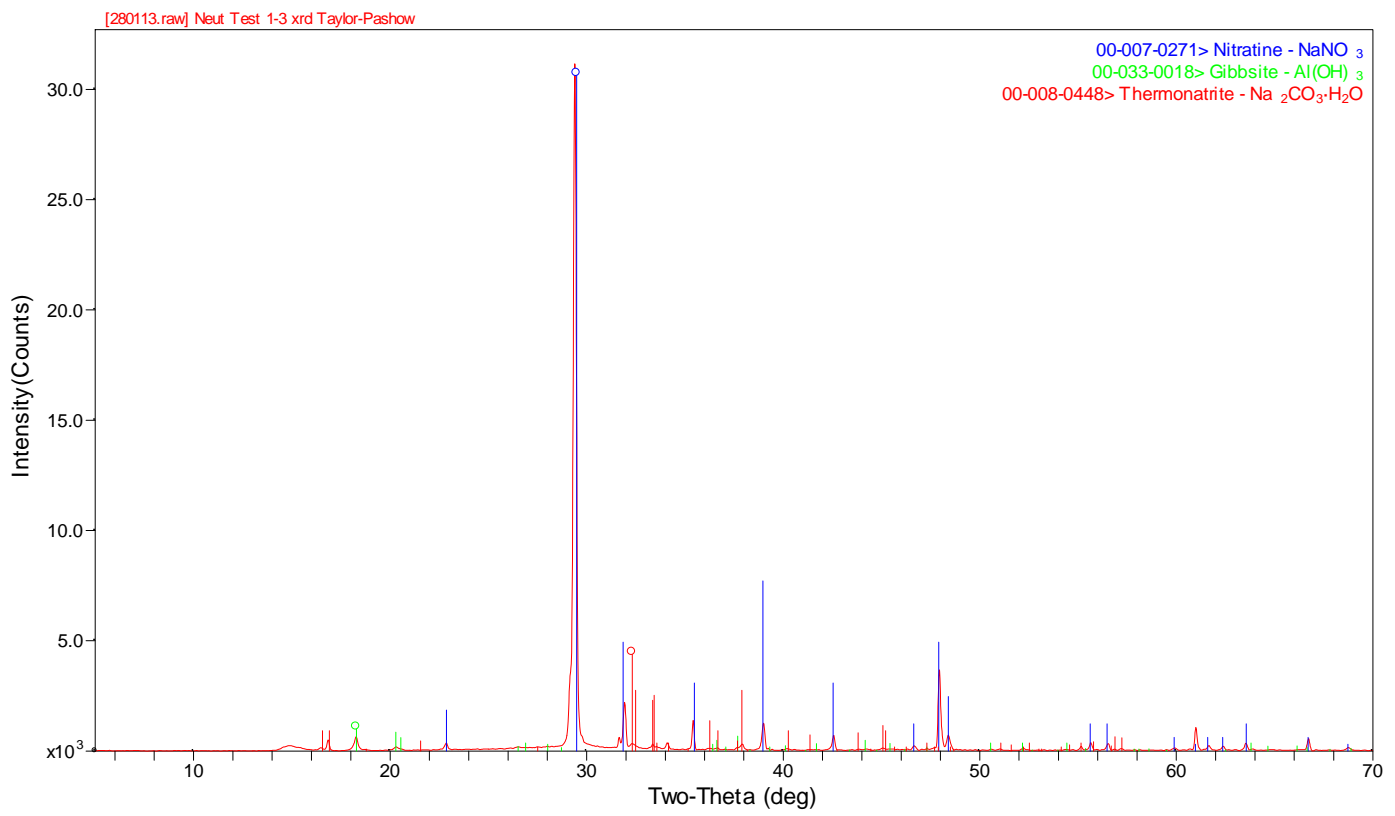

Figure 3. Powder XRD diffraction pattern of solids from Test 1-3.

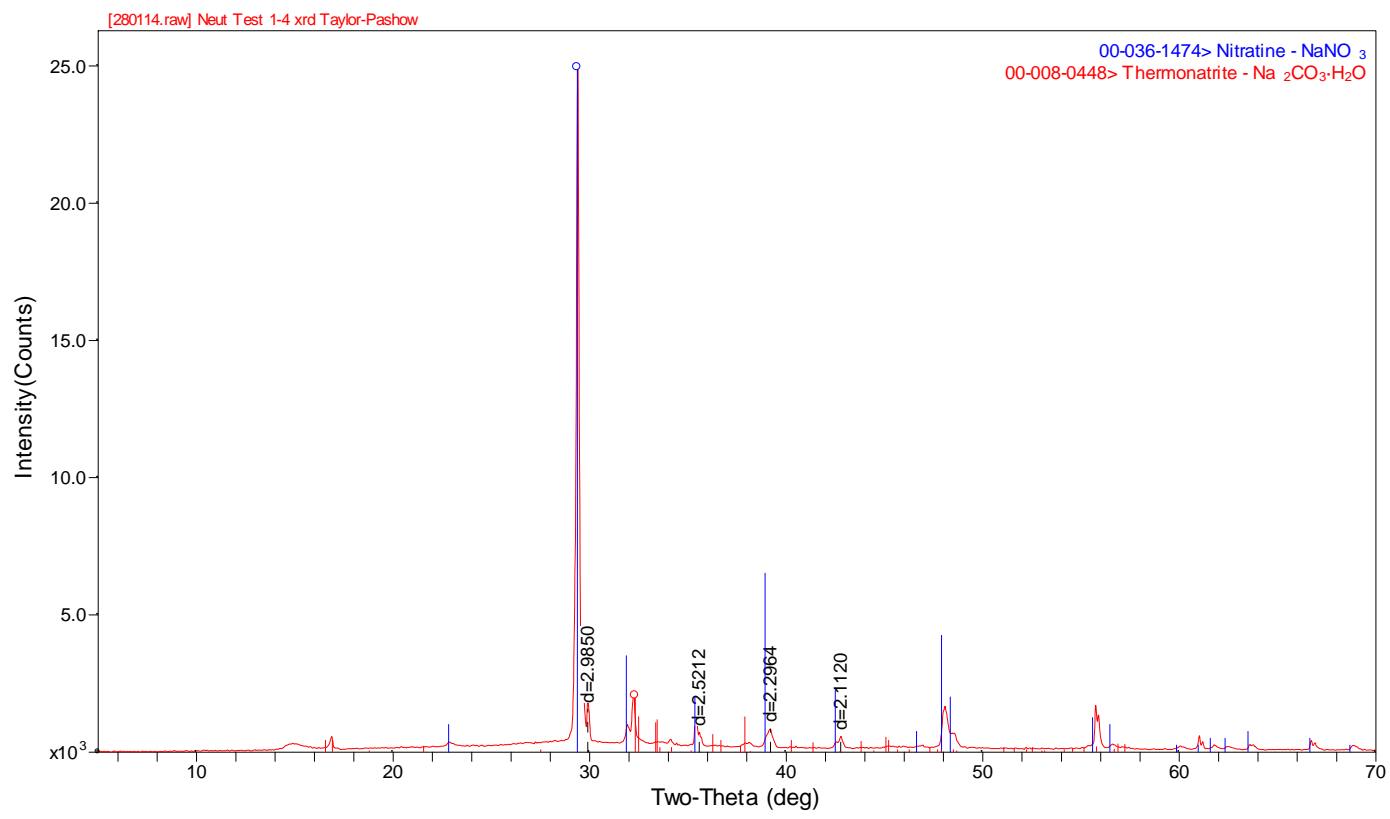

Figure 4. Powder XRD diffraction pattern of solids from Test 1-4. 
SRNL-STI-2011-00316

Revision 0

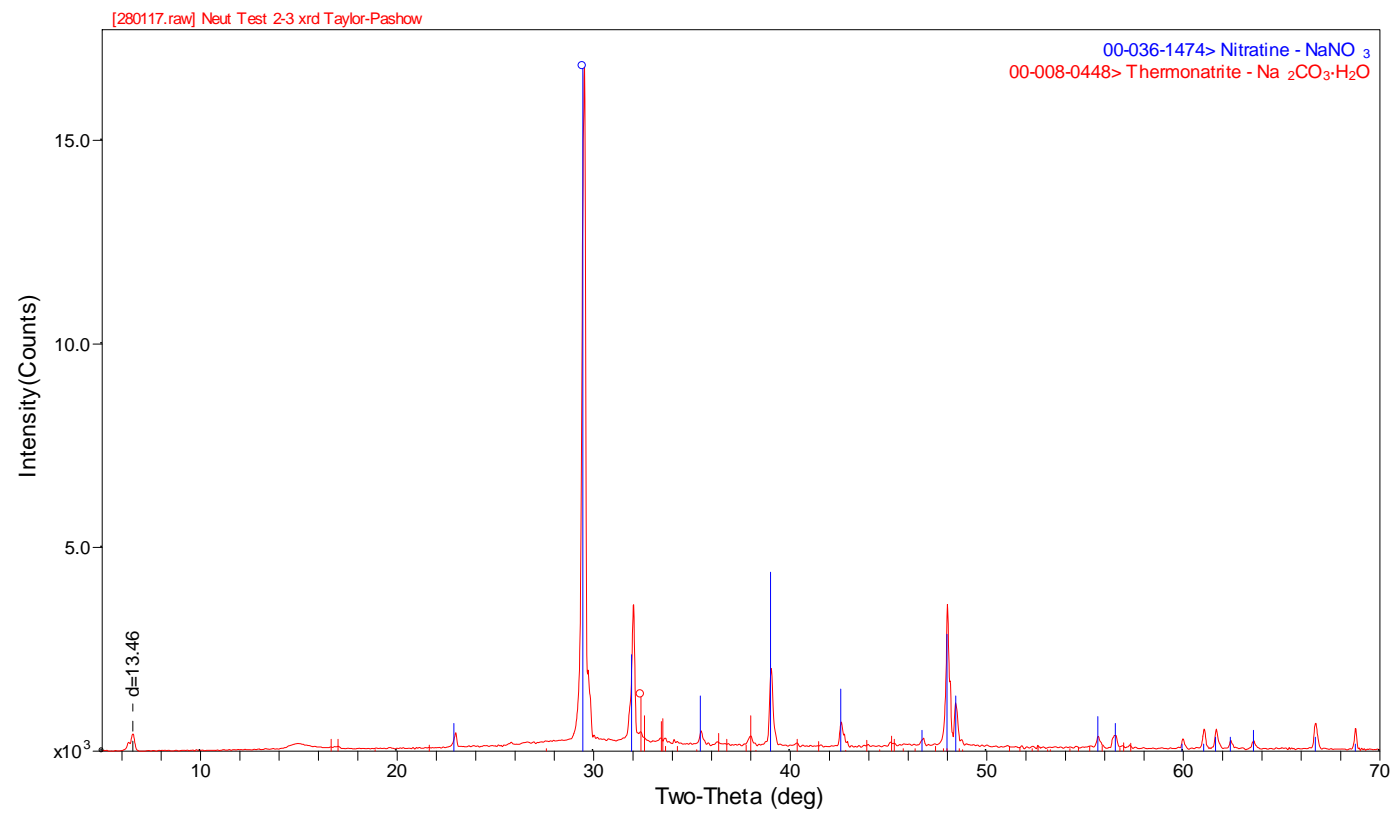

Figure 5. Powder XRD diffraction pattern of solids from Test 2-3.

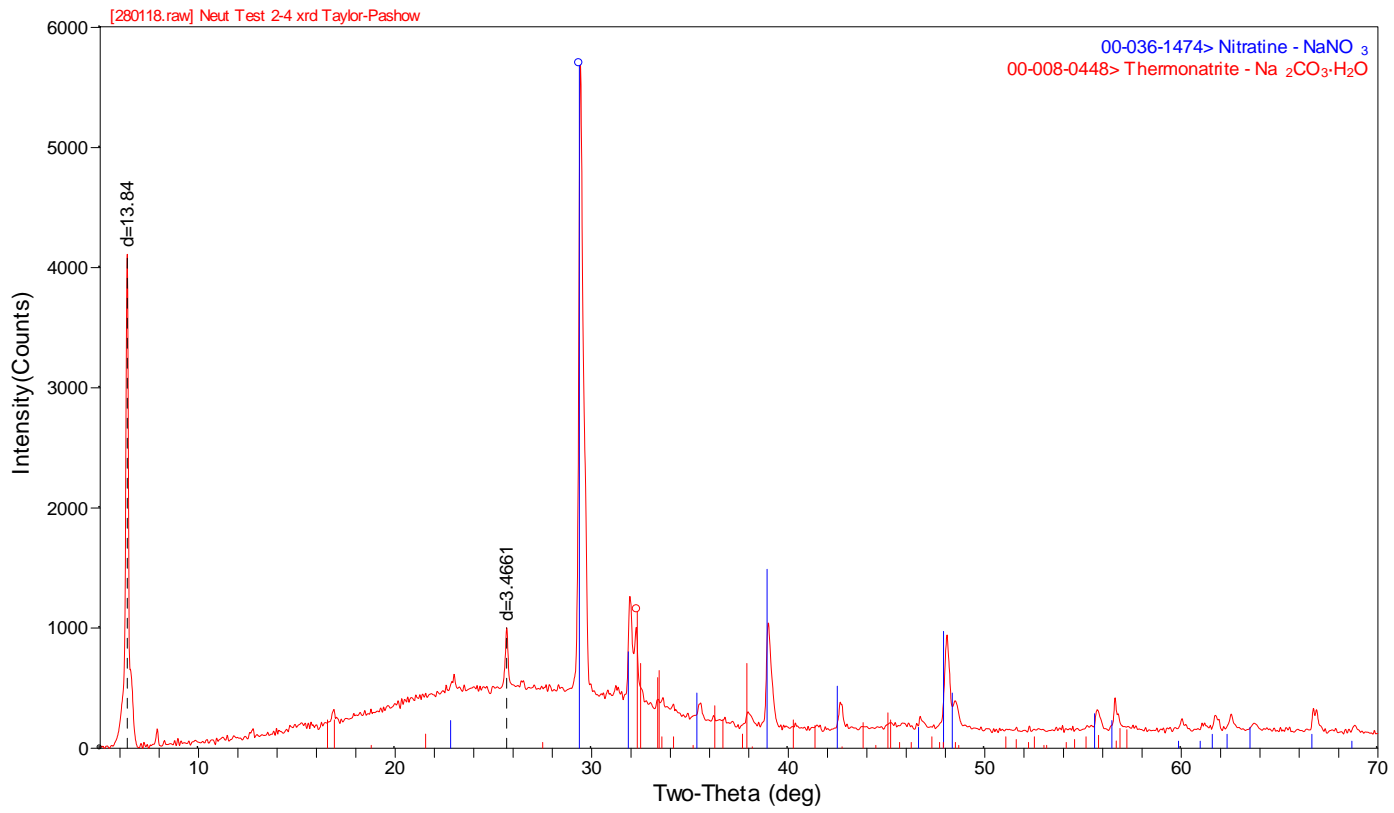

Figure 6. Powder XRD diffraction pattern of solids from Test 2-4. 


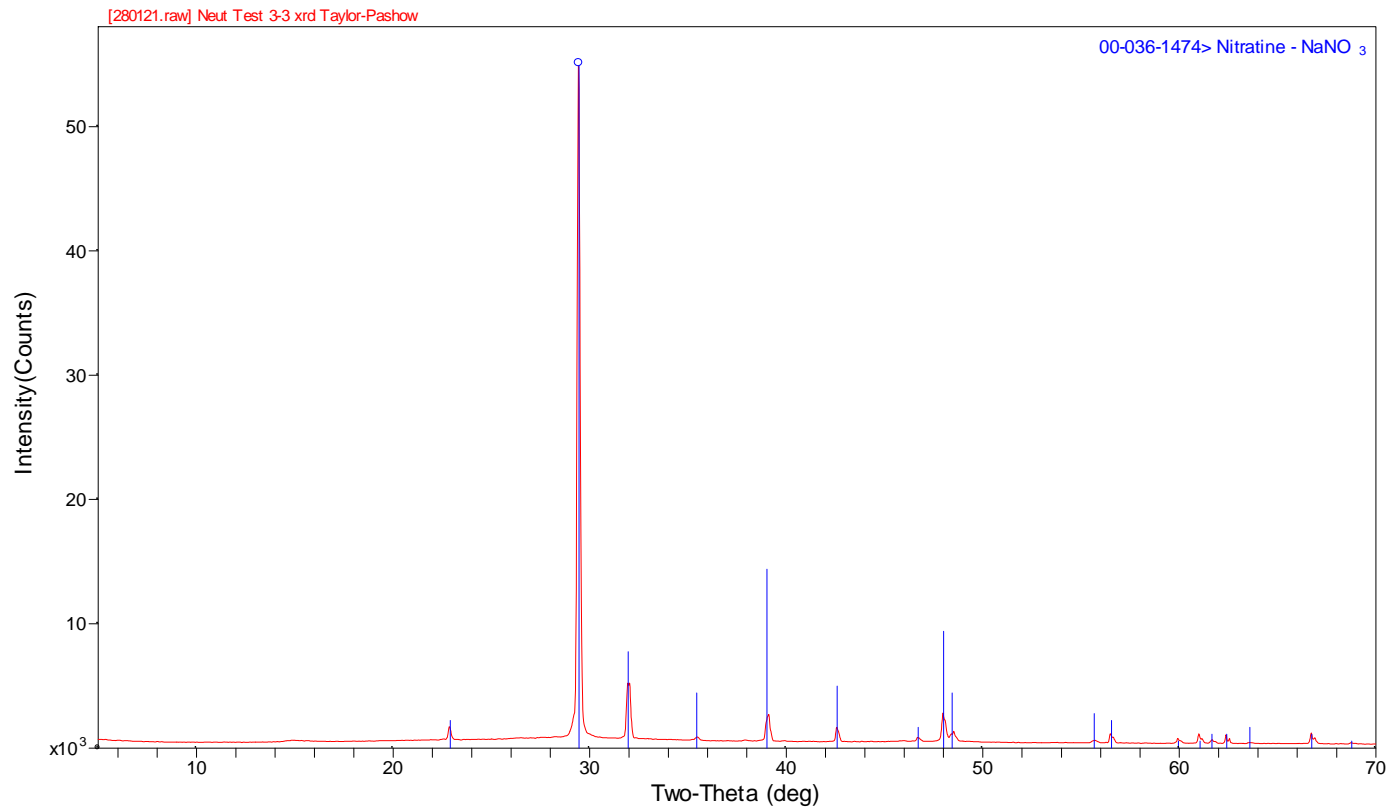

Figure 7. Powder XRD diffraction pattern of solids from Test 3-3.

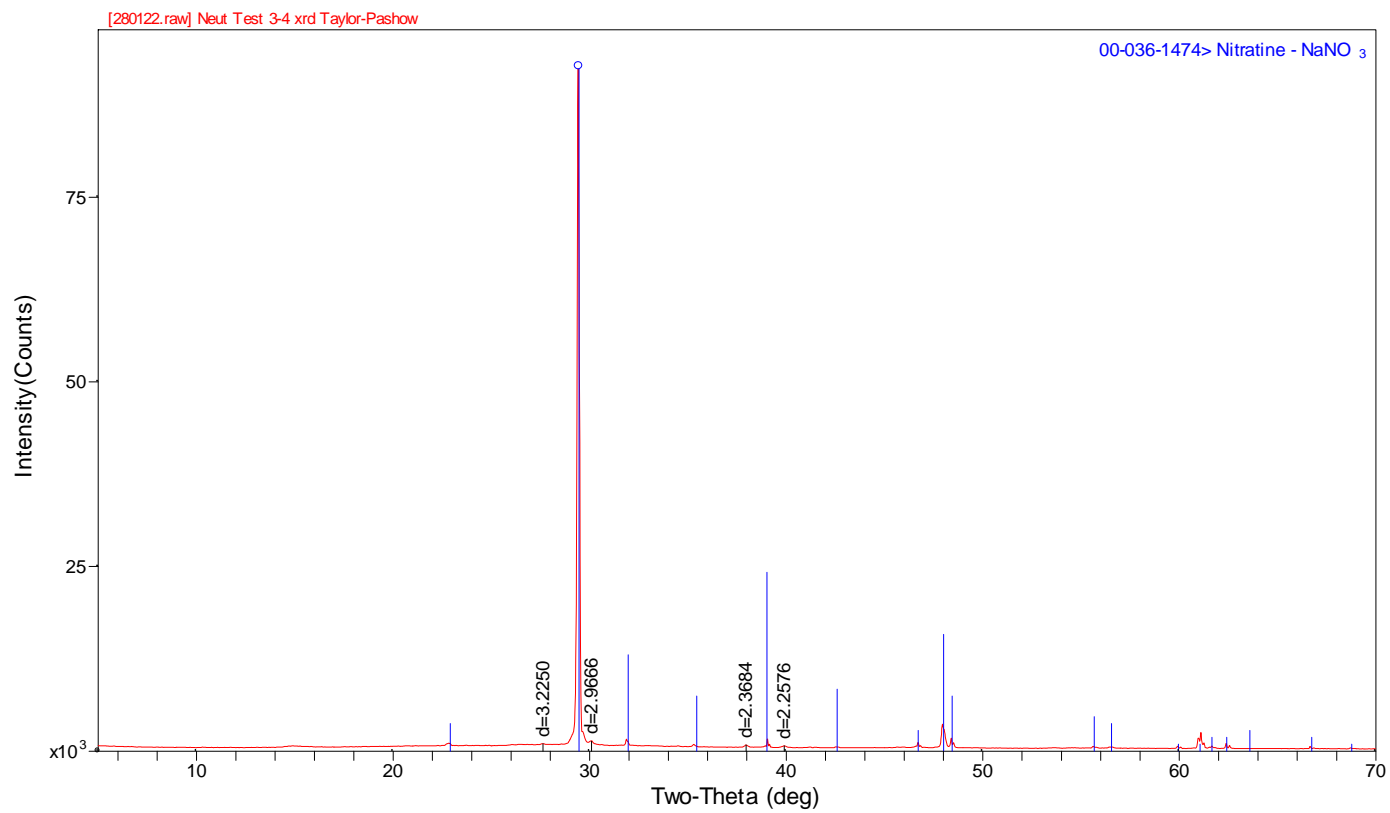

Figure 8. Powder XRD diffraction pattern of solids from Test 3-4.

\subsection{Density Measurements}

Neutralized solution densities were measured using two different methods. The two different methods were used to determine densities for two different conditions, first for normal processing, and second to determine the density of solids settled in a pump box. The first density 
measurement was from the initial beaker in which the neutralizations were performed. After settling for one day $5 \mathrm{~mL}$ of the supernate was weighed. The supernate was returned to the beaker. The mixture was then stirred and a $5-\mathrm{mL}$ aliquot of the slurry was removed and weighed. These densities are listed under "Supernate - Method 1" and "Slurry - Method 1" in Table 3-4. The second density measurements were from the graduated cylinder experiments performed to determine $\mathrm{H}$ ratios in the settled solids. In this experiment, $25 \mathrm{~mL}$ of slurried solution was allowed to settle for one week. Most of the supernate was removed and weighed to determine the density. This density was used to subtract the weight of the remaining volume of supernate $(0.4-$ $1.4 \mathrm{~mL}$ ). The remaining weight was that of the settled solids, from which their density was determined. These results are also provided in Table 3-4, under "Method 2".

Table 3-4. Neutralized Solution Densities

\begin{tabular}{|c|c|c|c|c|c|}
\hline Test & $\begin{array}{c}\text { Supernate } \\
\text { Density - } \\
\text { Method 1 (g/mL) }\end{array}$ & $\begin{array}{c}\text { Slurry Density } \\
- \text { Method 1 } \\
\mathbf{( g / m L )}\end{array}$ & $\begin{array}{c}\text { Supernate } \\
\text { Density - } \\
\text { Method 2 (g/mL) }\end{array}$ & $\begin{array}{c}\text { Slurry Density } \\
- \text { Method 2 } \\
\mathbf{( g / m L )}\end{array}$ & $\begin{array}{c}\text { Solids Density } \\
- \text { Method 2 } \\
(\mathbf{g} / \mathbf{m L})\end{array}$ \\
\hline $1-3$ & 1.396 & 1.387 & 1.375 & 1.439 & 1.507 \\
\hline $1-4$ & 1.337 & 1.296 & 1.345 & 1.414 & 1.429 \\
\hline $2-3$ & 1.408 & 1.390 & 1.379 & 1.406 & 1.409 \\
\hline $2-4$ & 1.379 & 1.377 & 1.405 & 1.426 & 1.433 \\
\hline $3-3$ & 1.345 & 1.346 & 1.328 & 1.337 & 1.357 \\
\hline $3-4$ & 1.344 & 1.354 & 1.324 & 1.344 & 1.440 \\
\hline
\end{tabular}

Both results are within the range expected for neutralized canyon waste. The densities are slightly higher than previous work, ${ }^{1-3}$ which is expected due to the higher $\mathrm{NaNO}_{3}$ concentrations in these solutions $(6.5-7.5 \mathrm{M})$. The density of $6.2 \mathrm{M} \mathrm{NaNO}_{3}$ is $1.3175 \mathrm{~g} / \mathrm{mL}$. ${ }^{9}$ As noted in previous studies, the difference in the supernate and settled solids densities is small. This result is consistent with the ease of mixing observed with the neutralized solutions.

\subsection{Settling Experiments}

The settling curves for each precipitate slurry (last 2 endpoints for each simulant) are shown in Figures 9-11. For Simulant 1, the $0.8 \mathrm{M}$ free hydroxide slurry (Test 1-3) settled quicker, and to a greater extent than the $1.2 \mathrm{M}$ free hydroxide slurry (Test 1-4). The Test 1-3 solids settled to approximately $53 \%$ of the original volume after approximately 3 days and $46 \%$ after one week. In comparison, after 3 days the solids from Test $1-4$ had only settled to approximately $91 \%$ of the original volume after 3 days, and $78 \%$ after one week. The solids from the neutralizations of Simulant 2 were slowest to settle, and only reached volumes of $70 \%$ and $89 \%$ of the original volumes after one week of settling, for the $1.2 \mathrm{M}$ free hydroxide and $0.8 \mathrm{M}$ free hydroxide slurries, respectively. The solids from the neutralization of Simulant 3 were the most rapid to settle, and settled to the greatest extent. After 24 hours the solids from Test 3-3 had settled to $46 \%$ of the original volume, and reached a final volume of $28 \%$ of the original volume after one week. The solids from Test 3-4 settled to $22 \%$ of the original volume after 24 hours, and reached a final volume of $16 \%$ of the original volume after one week. The reason for the more extensive settling for the Simulant 3 solids could be due to the larger average particle size, compared to the solids from Simulants 1 and 2.

\subsection{Particle Size Analysis}

The particle size distributions of the precipitated solids were measured using a Leeds and Northrup Microtrac II particle size analyzer. Particle size distributions, based on number percentage, for the fully neutralized (1.2 M free hydroxide) solutions are compared in Figure 12. The generated solids from Simulants 1 and 2 had very similar particle size distributions, with $\sim 85-89 \%$ of the particles being less than 2 microns. The solids generated from the neutralization 
of Simulant 3 had slightly larger particle sizes, with only $62 \%$ being below 2 micron, but $87 \%$ were below 4 micron. The particles from these neutralizations are generally smaller than what was seen in the previous work. ${ }^{3}$ The volume distribution is shown in Figure 13 for comparison.

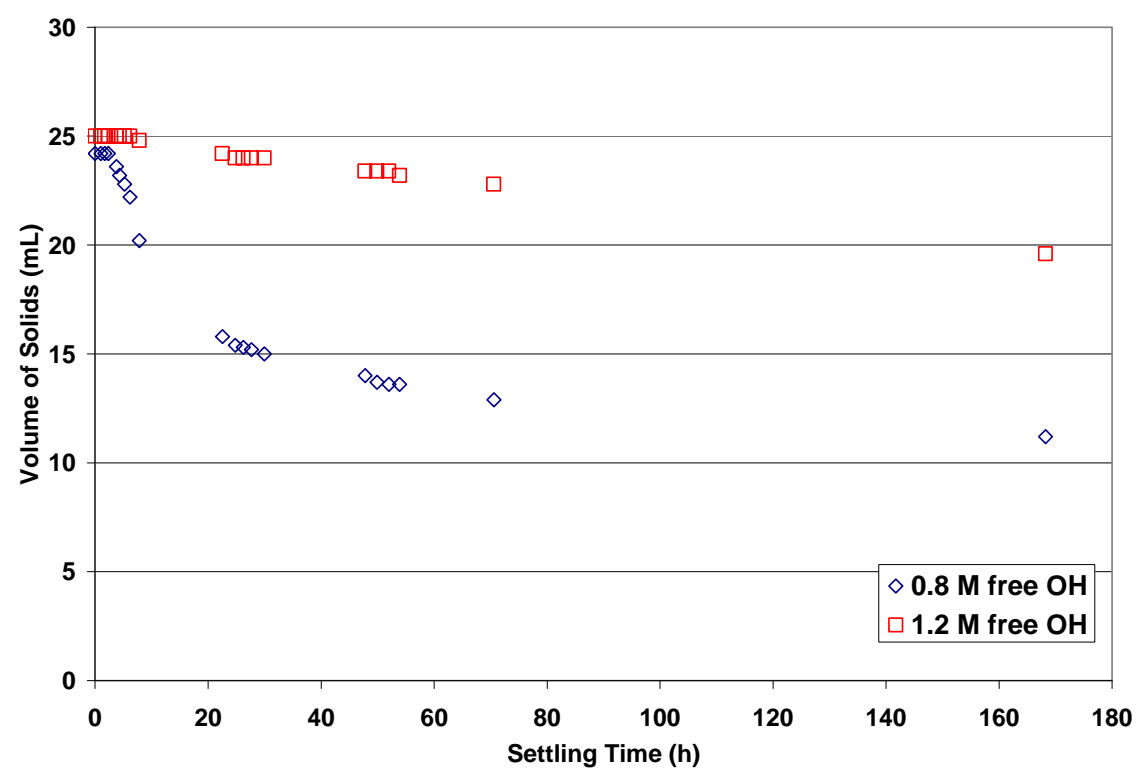

Figure 9. Settling rate of solids formed from the neutralizations of Simulant $1\left(0.5 \mathrm{M} \mathrm{HNO}_{3}\right.$, Tests 1-3 and 1-4).

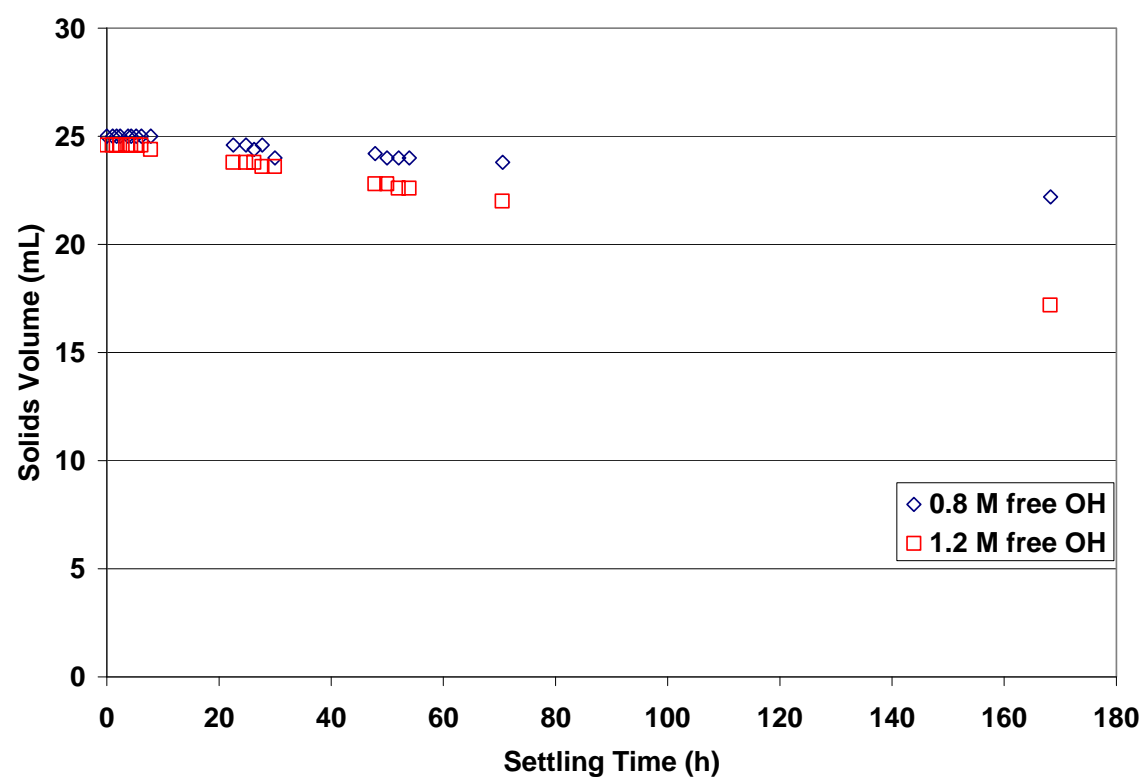

Figure 10. Settling rate of solids formed from the neutralizations of Simulant $2(1.0 \mathrm{M}$ $\mathrm{HNO}_{3}$, Tests 2-3 and 2-4). 


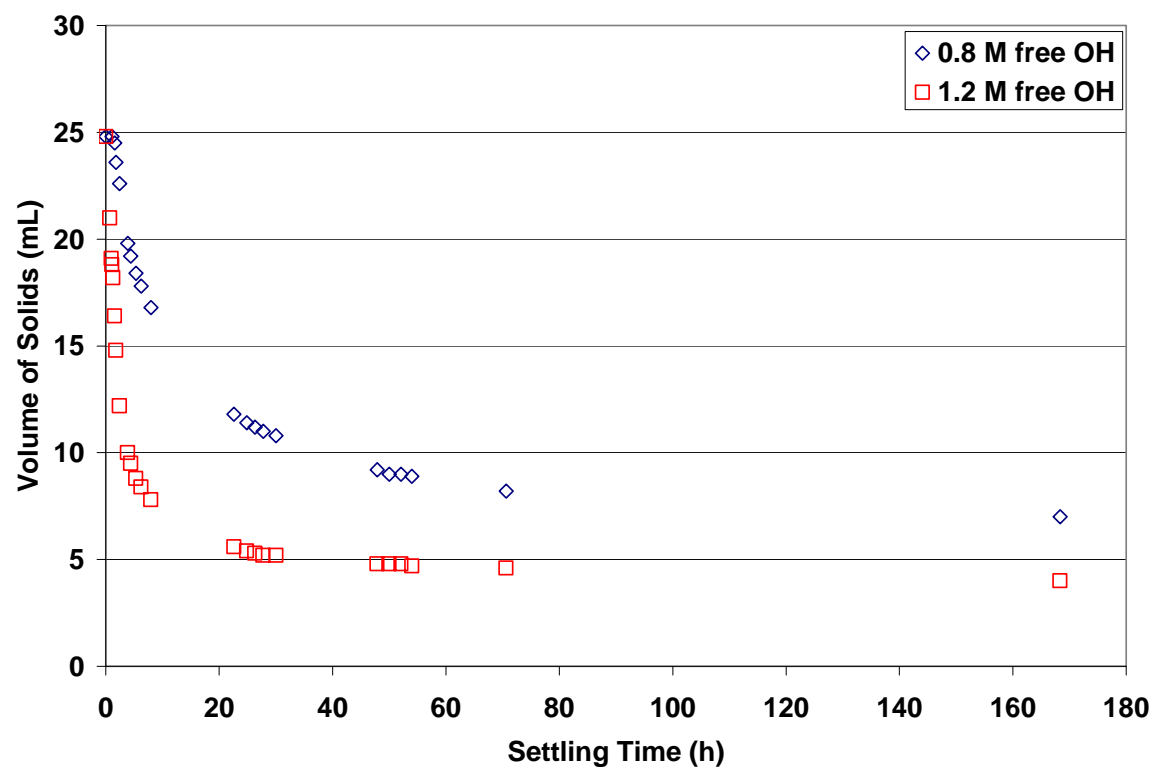

Figure 11. Settling rate of solids formed from the neutralizations of Simulant 3 (1.5 $\mathrm{M}$ $\mathrm{HNO}_{3}$, Tests 3-3 and 3-4).

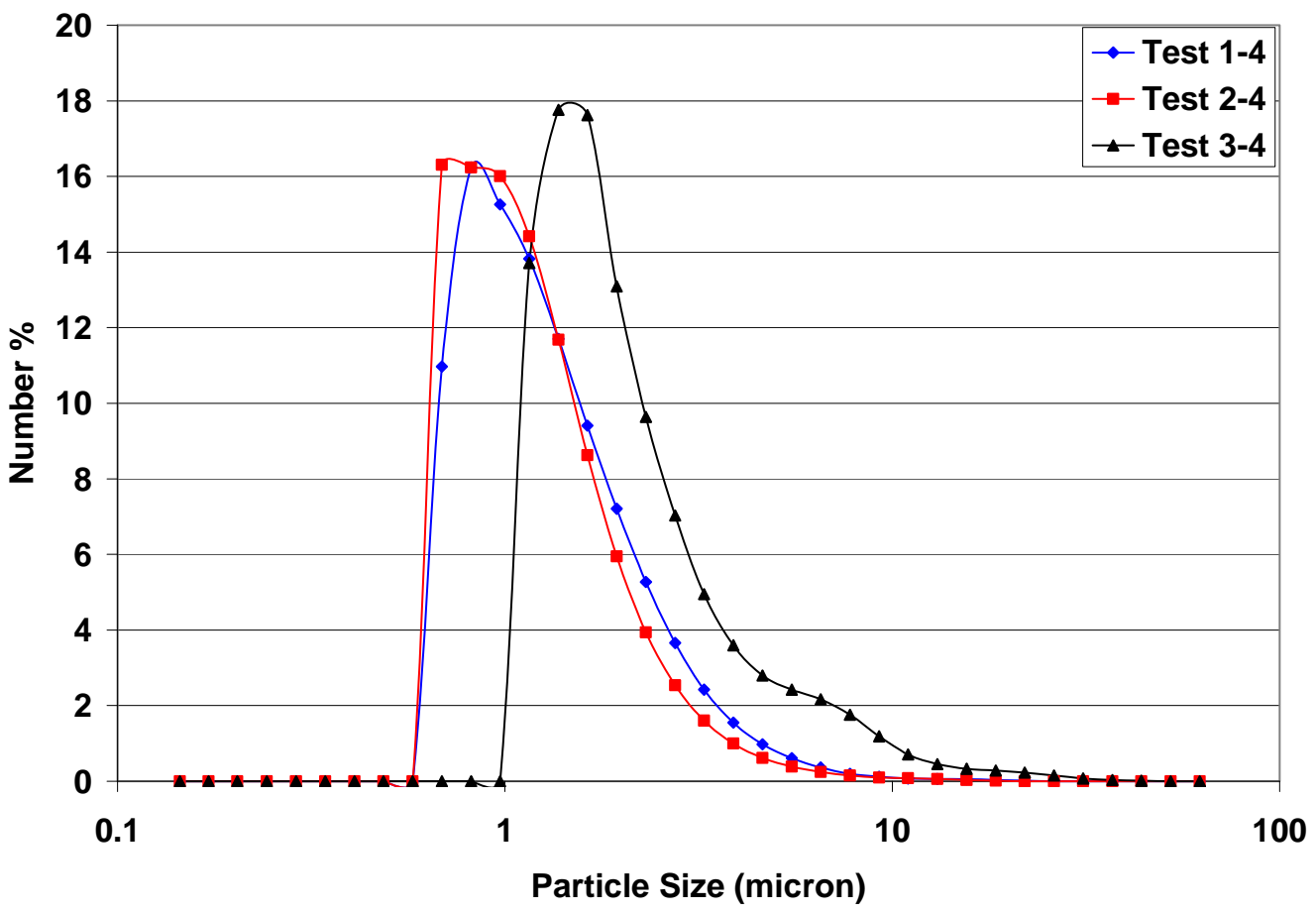

Figure 12. Number percentage particle size distributions for fully neutralized solutions (1.2 M free hydroxide). 
SRNL-STI-2011-00316

Revision 0

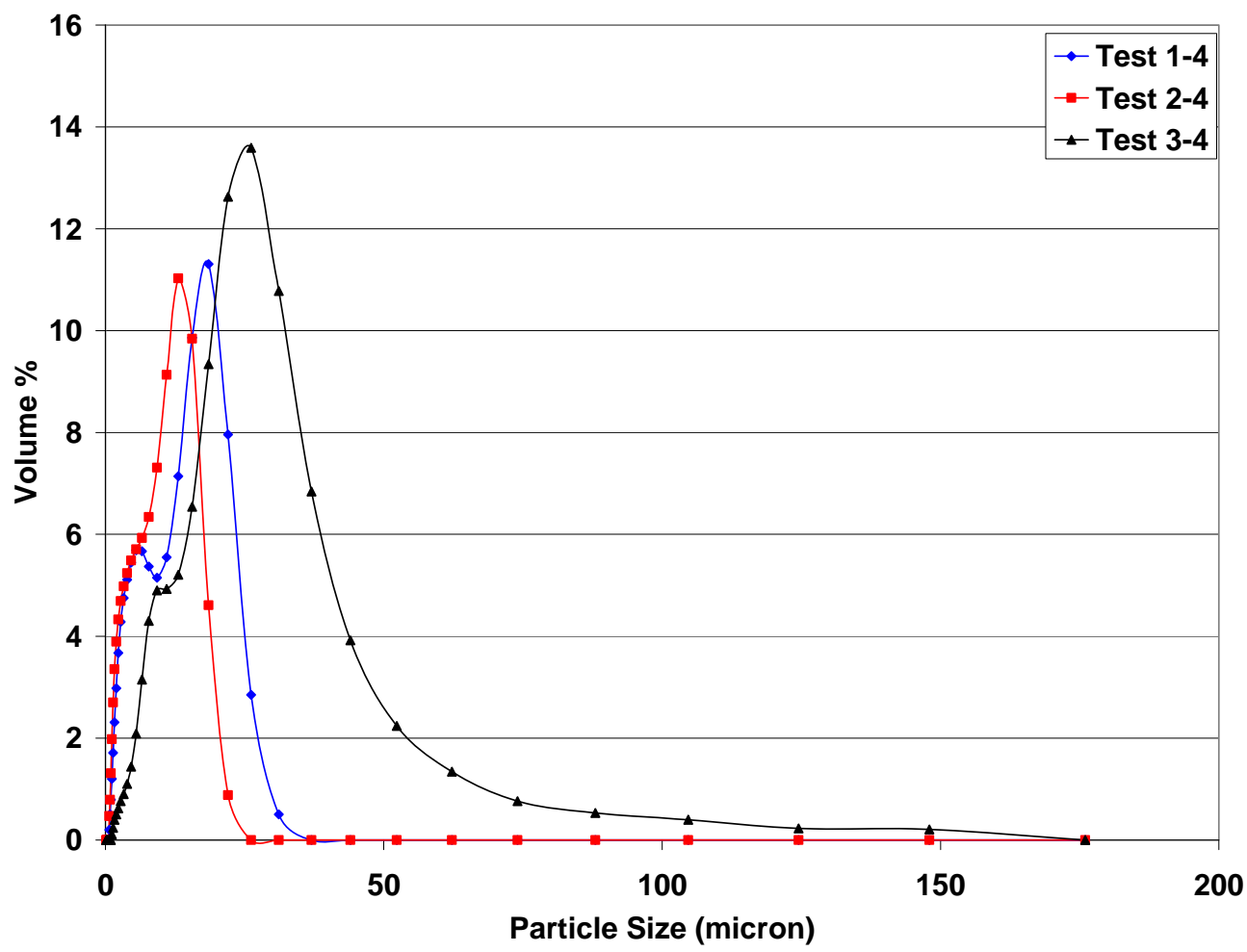

Figure 13. Volume percentage particle size distributions for fully neutralized solutions (1.2 M free hydroxide).

\section{$3.8 \underline{\mathrm{H}: \mathrm{U} \text { Ratios }}$}

\subsubsection{TGA}

The thermogravimetric analyses for the solids generated by the neutralization of the three simulants to the last two endpoints $(0.8 \mathrm{M}$ and $1.2 \mathrm{M}$ free hydroxide) are shown in Figure 14 . All of the TGA results for the solids from the test solutions were similar, having a single mass loss step corresponding to the temperature expected for $\mathrm{H}_{2} \mathrm{O}$ removal. The mass loss at $300{ }^{\circ} \mathrm{C}$ was used to determine the amount of water in the centrifuged solids. 


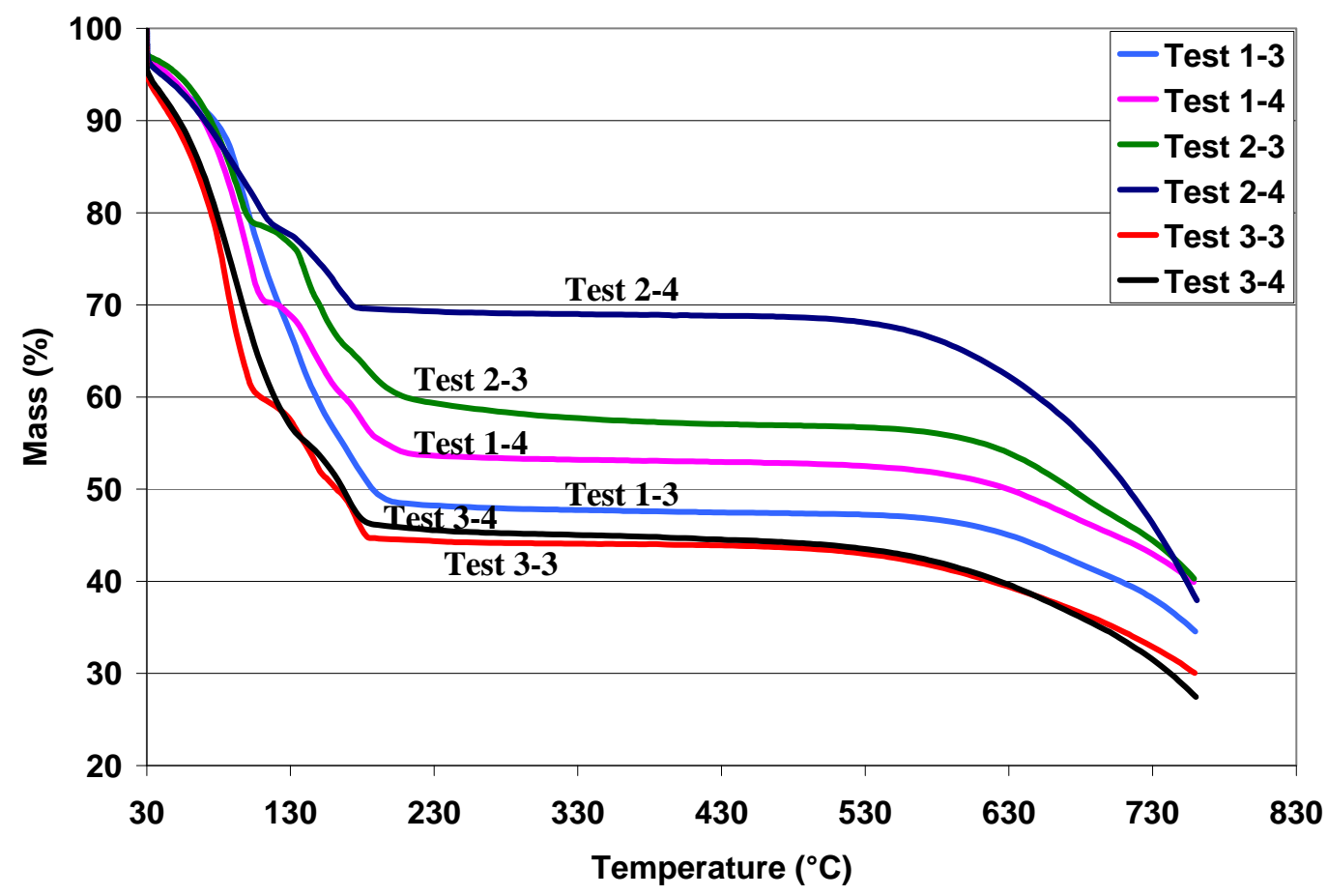

Figure 14. TGA results for centrifuged solids from the three $U / G d$ solutions neutralized to the last two endpoints (0.8 $\mathrm{M}$ and $1.2 \mathrm{M}$ free hydroxide).

The H:U molar ratios of the centrifuged solids from the TGA analysis are given in Table 3-5. These ratios represent minimum values, as the ratios were calculated assuming that the solids were composed of $\mathrm{Na}_{2} \mathrm{U}_{2} \mathrm{O}_{7}, \mathrm{Gd}(\mathrm{OH})_{3}$, and $\mathrm{Al}(\mathrm{OH})_{3}$. However, based on the XRD results, the solids also contained a large amount of $\mathrm{NaNO}_{3}$. Therefore, the moles of $\mathrm{U}$ calculated to be in the solids represents a maximum value, and the $\mathrm{H}: \mathrm{U}$ molar ratio is therefore a minimum value, and the true value is likely much higher. In addition the $\mathrm{H}$ from the hydroxides is not taken into account, further making these calculated values conservative. Representative calculations of the $\mathrm{H}$ ratios for the centrifuged solids are given in Appendix D.

\section{Table 3-5. H:U Ratios in Centrifuged Solids}

\begin{tabular}{|c|c|c|}
\hline Test & $\begin{array}{c}\text { Mass Loss at } \\
\mathbf{3 0 0}{ }^{\circ} \mathbf{C}\end{array}$ & $\begin{array}{c}\text { Minimum H:U Molar } \\
\text { Ratio }\end{array}$ \\
\hline $\mathbf{1 - 3}$ & $52.18 \mathrm{wt} \%$ & 1530 \\
\hline $\mathbf{1 - 4}$ & $46.73 \mathrm{wt} \%$ & 1090 \\
\hline $\mathbf{2 - 3}$ & $41.97 \mathrm{wt} \%$ & 1010 \\
\hline $\mathbf{2 - 4}$ & $30.96 \mathrm{wt} \%$ & 240 \\
\hline $\mathbf{3 - 3}$ & $55.88 \mathrm{wt} \%$ & 1340 \\
\hline $\mathbf{3 - 4}$ & $54.86 \mathrm{wt} \%$ & 830 \\
\hline
\end{tabular}

\subsubsection{Graduated Cylinder Tests}

The water content in the settled solids was based on the evaporated mass from both the solids settled after 1 week and from the supernate. This mass was used to calculate the H:U molar ratio 
for the solids generated by the neutralization of the three $\mathrm{U} / \mathrm{Gd}$ solutions to the last two endpoints (0.8 $\mathrm{M}$ and 1.2 $\mathrm{M}$ free hydroxide). The $\mathrm{H}$ ratios are summarized in Table 3-6. The H:U ratio could not be accurately determined for the solids from Test 1-3, due to the incomplete transfer of the settled solids from the graduated cylinder to the beaker. Sample calculations for these values are presented in Appendix E.

Table 3-6. H:U Molar Ratios in One-Week Settled Solids

\begin{tabular}{||c|c|c||c|c|c||}
\hline \hline Test & Endpoint & $\begin{array}{c}\text { H:U Molar } \\
\text { Ratio }\end{array}$ \\
\hline $1-3$ & $0.8 \mathrm{M} \mathrm{OH}^{-}$ & Nest & Endpoint & $\begin{array}{c}\text { H:U Molar } \\
\text { Ratio }\end{array}$ \\
\hline $2-3$ & $0.8 \mathrm{M} \mathrm{OH}^{-}$ & 1900 \\
\hline $3-3$ & $0.8 \mathrm{M} \mathrm{OH}^{-}$ & 771 \\
\hline \multicolumn{4}{|c|}{$\mathrm{ND}=$ not determined } & $1.2 \mathrm{M} \mathrm{OH}^{-}$ & 4020 \\
\hline $2-4$ & $1.2 \mathrm{M} \mathrm{OH}^{-}$ & 388 \\
\hline
\end{tabular}

The H:U molar ratios presented in Table 3-5 and 3-6 represent two accident scenarios. The first was for the solids drying out in an unagitated pump box. Experimentally, this scenario was determined by measuring the H:U molar ratio in centrifuged solids. The minimum H:U atom ratios for centrifuged U/Gd solids ranged from 240:1 to 1530:1. The fully neutralized solids were found, in general, to have slightly lower $\mathrm{H}: \mathrm{U}$ molar ratios than the solids from the partially neutralized $(0.8 \mathrm{M}$ free hydroxide) samples. These ratios are similar to what was observed in the previous work. ${ }^{3}$ The second accident scenario is for transient neutralization and agitator failure. Experimentally this scenario was determined by measuring the $\mathrm{H}: \mathrm{U}$ molar ratio of the settled solids. The H:U molar ratios for solids from the fully neutralized solutions ranged from 388:1 to 4020:1. Similar H:U molar ratios were also calculated for solids from the partial neutralization (to $0.8 \mathrm{M}$ free hydroxide), ranging from $771: 1$ to $1900: 1$. Since the Gd:U mass ratio was found to be at least 1.0 in all of the precipitated solids, the minimum safe $\mathrm{H}: \mathrm{U}$ molar ratio needed is only 30:1, assuming a $1: 1$ equivalence with ${ }^{239} \mathrm{Pu}$ (Figure 15). ${ }^{10}$

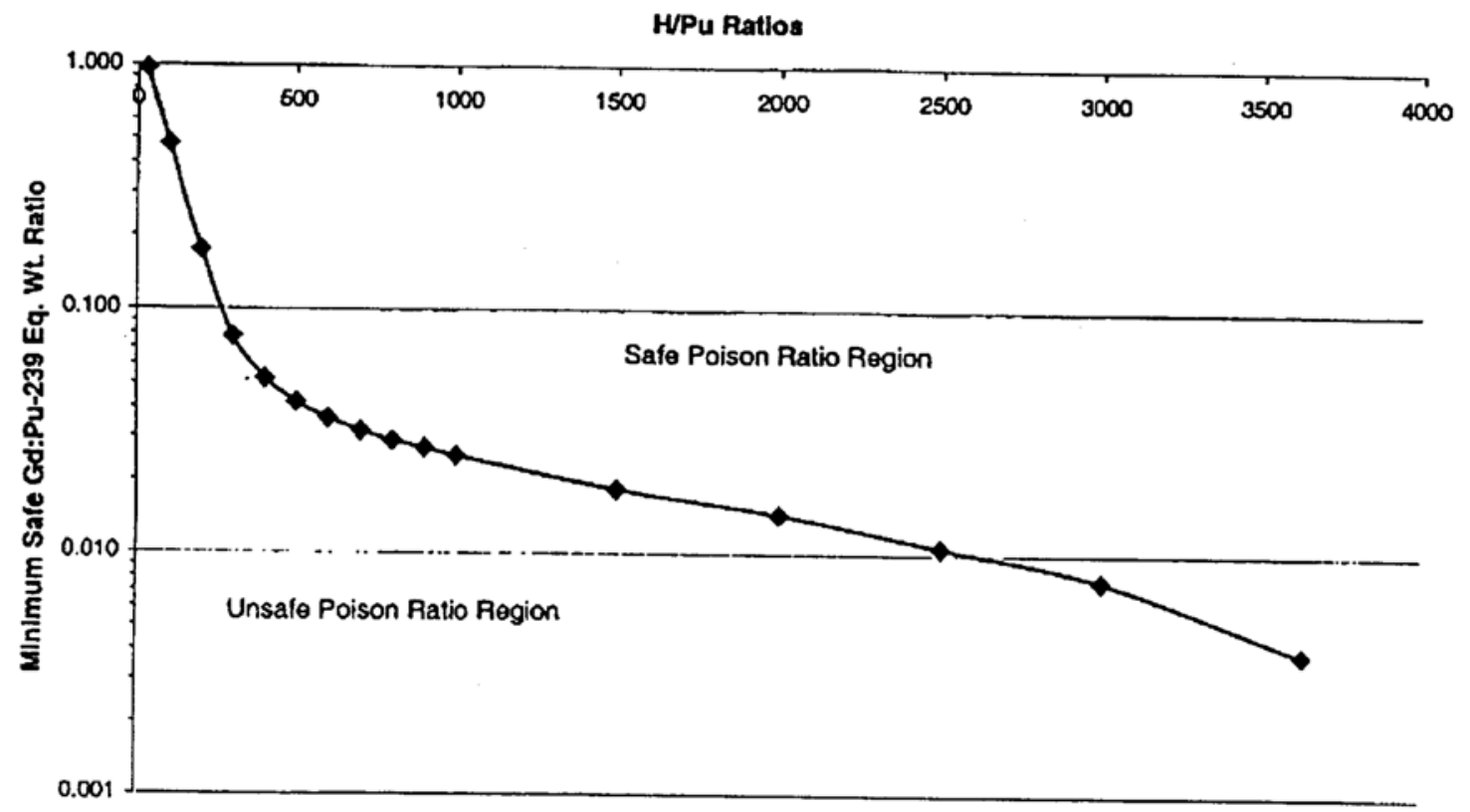

Figure 15. Safe amount of Gd needed for differing H:Pu molar ratios (reproduced from ref. 10). 


\subsection{Conclusions}

Gadolinium was found to be a viable poison for the neutralization of High Al/Low U UNF solution in three different nitric acid concentration, $0.5,1.0$, and $1.5 \mathrm{M}$. The amount of Gd added to these solution was at a $1.15: 1 \mathrm{Gd}: \mathrm{U}$ mass ratio. Based on particle size analysis, the solids generated from the neutralization of Simulants $1(0.5 \mathrm{M}$ acid $)$ and $2(1.0 \mathrm{M}$ acid $)$ were less than 20 microns in size. Over $99.5 \%$ of the solids generated from the full neutralization of the highest $(1.5 \mathrm{M})$ acid simulant, Simulant 3, were also below 20 microns. These results indicate that selfshielding will not have an impact on the criticality safety of these precipitates. SEM/EDS analysis showed some evidence of larger crystals, but these were identified as $\mathrm{NaNO}_{3}$. The Gd:U mass ratio was found to be at least 1.0 in the solids at each of the neutralization endpoints for all three simulants, therefore the minimum H:U molar ratio needed is only 30:1, which was exceeded in both accident scenarios tested.

Based on the results of this testing, neutralization of solutions with the following composition to $1.2 \mathrm{M}$ free hydroxide can be safely performed using $\mathrm{Gd}$ as a poison: $0.5-1.5 \mathrm{M} \mathrm{HNO}_{3}, 0.002 \mathrm{M}$ $\mathrm{Hg}, 2.0 \mathrm{M} \mathrm{Al}, 1.5 \mathrm{~g} / \mathrm{L} \mathrm{U}$, and $1.725 \mathrm{~g} / \mathrm{L} \mathrm{Gd}$. 


\subsection{References}

1. M. G. Bronikowski, J. H. Gray, B. C. Hill, F. R. Graham, and D. G. Karraker, "Caustic Precipitation of Plutonium using Gadolinium as the Neutron Poison for Disposition to High Level Waste", WSRC-TR-2002-00198, May 2002.

2. A. E. Visser, T. S. Rudisill, and M. G. Bronikowski, "Investigation of Plutonium and Uranium Precipitation Behavior with Gadolinium as a Neutron Poison", WSRC-TR2003-00193, May 2003.

3. M. G. Bronikowski and T. S. Rudisill, "Neutralization of Plutonium and Enriched Uranium Solutions Containing Gadolinium as a Neutron Poison", WSRC-TR-200400053, February 2004.

4. W. H. Clifton, "Flowsheet Evaluation for the Neutralization of High Aluminum - Low Uranium UNF Solution,” NMMD-HTS-2010-3161, Rev. 0, September 2010.

5. K. M. L. Taylor-Pashow, "Task Technical and Quality Assurance Plan - Flowsheet Evaluation for the Neutralization of High Aluminum - Low Uranium Used Nuclear Fuel (UNF) Solution," SRNL-RP-2010-01655, Rev. 0, November 2010.

6. A. C. Vermeulen, J. W. Geus, R. J. Stol, and P. L. De Bruyn, "Hydrolysis-Precipitation Studies of Aluminum(III) Solutions I. Titration of Acidified Aluminum Nitrate Solutions", J. Colloid and Interface Science, 1975, 51, 449-458.

7. C. E. Picket, "Aluminum and Boron Solids in SFO First Cycle Feed", NMS-EHA980072, May 12, 1998.

8. A. S. Russell, J. D. Edwards, and C. S. Taylor, "Solubility and Density of Hydrated Aluminas in NaOH Solutions", J. of Metals, 1955, 1123-1128.

9. "Concentrative Properties of Aqueous Solutions: Density, Refractive Index, Freezing Point Depression, and Viscosity," in CRC Handbook of Chemistry and Physics, 91st Edition (Internet Version 2011), W. M. Haynes, ed., CRC Press/Taylor and Francis, Boca Raton, FL.

10. K. J. McCoid, "Nuclear Criticality Safety Evaluation: Minimum Safe Gadolinium to Plutonium Ratio in an Infinite System” N-NCS-H-00134, Rev. 0, May 2002. 
SRNL-STI-2011-00316

Revision 0

Appendix A 


\section{Appendix A: Procedure to Measure Water Content of Settled Solids}

The water content of the settled solids produced during the neutralization of each simulant to the final two endpoints $(0.8 \mathrm{M}$ and $1.2 \mathrm{M}$ free hydroxide) was measured using the following procedure.

1. Determine the mass of an empty $25-\mathrm{mL}$ graduated cylinder.

2. While stirring, transfer $25 \mathrm{~mL}$ of the supernate and solids to the graduated cylinder and determine the mass.

3. Allow the solids to settle (took approximately 1 week for setting to complete).

4. Determine the mass of two $100-\mathrm{mL}$ beakers.

5. Record the volume of supernate above the settled solids.

6. Transfer the majority of the supernate to one of the $100-\mathrm{mL}$ beakers, leaving $1-2 \mathrm{~mL}$ of supernate above the solids to ensure no solids are transferred to the beaker.

7. Determine the mass of the beaker and supernate removed from the graduated cylinder.

8. Record the volume of supernate remaining above the solids in the graduated cylinder.

9. Pour the remaining supernate and solids into the second $100-\mathrm{mL}$ beaker.

10. Determine the mass of the beaker and solids.

11. Rinse any remaining solids from the graduated cylinder into the second beaker using small aliquots of distilled water $(\sim 4 \mathrm{~mL})$.

12. Determine the mass of the beaker with solids and rinse water.

13. Allow the beakers to dry at ambient temperature.

14. Reweigh the beakers and dried solids.

The water associated with the settled solids is then calculated by difference using the mass and volume measurements obtained from the procedure above. 


\section{Appendix B}




\section{Appendix B: Sample Calculations for Gd Ratios and Extent of Precipitation}

The ICP-ES analyses for the solids and supernate generated from the neutralizations of Simulants 1-3 to all four endpoints are given in Table B-1. All sample dilutions have been taken into account.

Table B-1. ICP-ES Analyses for Al, Gd, and U

\begin{tabular}{|c|c|c|c|c|c|c|c|}
\hline \multirow{2}{*}{ Test } & Neutralization & \multicolumn{3}{|c|}{ Supernate } & \multicolumn{3}{c|}{ Solids } \\
\cline { 3 - 8 } & Endpoint & Al (mg/L) & Gd (mg/L) & U (mg/L) & Al (mg/L) & Gd (mg/L) & U (mg/L) \\
\hline $1-1$ & $\mathrm{pH} 4$ & 27100 & 1190 & 952 & 24000 & 559 & 508 \\
\hline $1-2$ & solid phase & $\mathrm{n} / \mathrm{a}$ & $\mathrm{n} / \mathrm{a}$ & $\mathrm{n} / \mathrm{a}$ & 17500 & 548 & 469 \\
\hline $1-3$ & $0.8 \mathrm{M}$ free $\mathrm{OH}^{-}$ & 28600 & 7.5 & $<44.5$ & 24200 & 1640 & 1400 \\
\hline $1-4$ & $1.2 \mathrm{M}$ free $\mathrm{OH}^{-}$ & 29400 & 7.24 & $<88.9$ & 23100 & 1740 & 1520 \\
\hline $2-1$ & $\mathrm{pH} \mathrm{3.5}$ & 29200 & 1190 & 982 & 17200 & 415 & 400 \\
\hline $2-2$ & solid phase & $\mathrm{n} / \mathrm{a}$ & $\mathrm{n} / \mathrm{a}$ & $\mathrm{n} / \mathrm{a}$ & 16600 & 524 & 453 \\
\hline $2-3$ & $0.8 \mathrm{M}$ free $\mathrm{OH}^{-}$ & 25700 & 5.97 & $<88.9$ & 22300 & 1500 & 1290 \\
\hline $2-4$ & $1.2 \mathrm{M}$ free $\mathrm{OH}^{-}$ & 29600 & 12 & $<88.9$ & 10000 & 1830 & 1630 \\
\hline $3-1$ & $\mathrm{pH} \mathrm{3.5}$ & 23100 & 1120 & 865 & 19100 & 420 & 410 \\
\hline $3-2$ & solid phase & $\mathrm{n} / \mathrm{a}$ & $\mathrm{n} / \mathrm{a}$ & $\mathrm{n} / \mathrm{a}$ & 20600 & 648 & 561 \\
\hline $3-3$ & $0.8 \mathrm{M}$ free $\mathrm{OH}^{-}$ & 25600 & 9.1 & $<88.9$ & 18700 & 1670 & 1460 \\
\hline $3-4$ & $1.2 \mathrm{M}$ free $\mathrm{OH}^{-}$ & 27100 & 7.17 & $<88.9$ & 11900 & 1730 & 1500 \\
\hline
\end{tabular}

Representative Calculations for the Results in Table 3-1

To determine the Gd:U ratio, the ICP-ES results for Gd were divided by those for U. For example, the ratio in the solids generated by partial neutralization $(\mathrm{pH} 4)$ of Simulant 1 (Test 1-1) is calculated below.

$559 \mathrm{mg} / \mathrm{L} \mathrm{Gd}$ in solids from ICP-ES

$508 \mathrm{mg} / \mathrm{L} \mathrm{U}$ in solids from ICP-ES

Gd:U Ratio $=\frac{559 \frac{\mathrm{mg}}{\mathrm{L}}}{508 \frac{\mathrm{mg}}{\mathrm{L}}}=1.10$

Representative Calculations for the Results in Table 3-2

The extents of precipitation of $\mathrm{Gd}, \mathrm{U}$, and $\mathrm{Al}$ from each of the neutralizations are shown in Table 3-2. These values were determined using the measured concentrations in the simulant. A sample calculation for determining the percent of $\mathrm{Gd}$ in the solids generated by the partial neutralization (pH 4) of Simulant 1 (Test 1-1) is shown below.

Calculation of Dilution Factor (from data in Table 2-2)

Initial volume of simulant $=25 \mathrm{~mL}$

Volume of $\mathrm{NaOH}$ added $=6.5 \mathrm{~mL}$

Final volume at end of neutralization $=31.5 \mathrm{~mL}$

Dilution Factor $=\frac{\text { InitialVol. }}{\text { FinalVol. }}=\frac{25 \mathrm{~mL}}{31.5 \mathrm{~mL}}=0.794$ 
Calculation of \% Gd in supernate and solids

Initial $\mathrm{Gd}$ concentration $=1.725 \mathrm{~g} / \mathrm{L}$

Final Gd concentration $=(1.725 \mathrm{~g} / \mathrm{L})(0.794)(1000 \mathrm{mg} / \mathrm{g})=1369 \mathrm{mg} / \mathrm{L}$

From ICP-ES - Gd concentration in supernate is $1190 \mathrm{mg} / \mathrm{L}$

$\% \mathrm{Gd}$ in supernate $=\frac{1190 \frac{\mathrm{mg}}{\mathrm{L}}}{1369 \frac{\mathrm{mg}}{\mathrm{L}}} \times 100 \%=86.9 \%$

$\%$ Gd in solids $=100 \%-86.9 \%=13.1 \%$ 


\section{Appendix C}


SRNL-STI-2011-00316

Revision 0
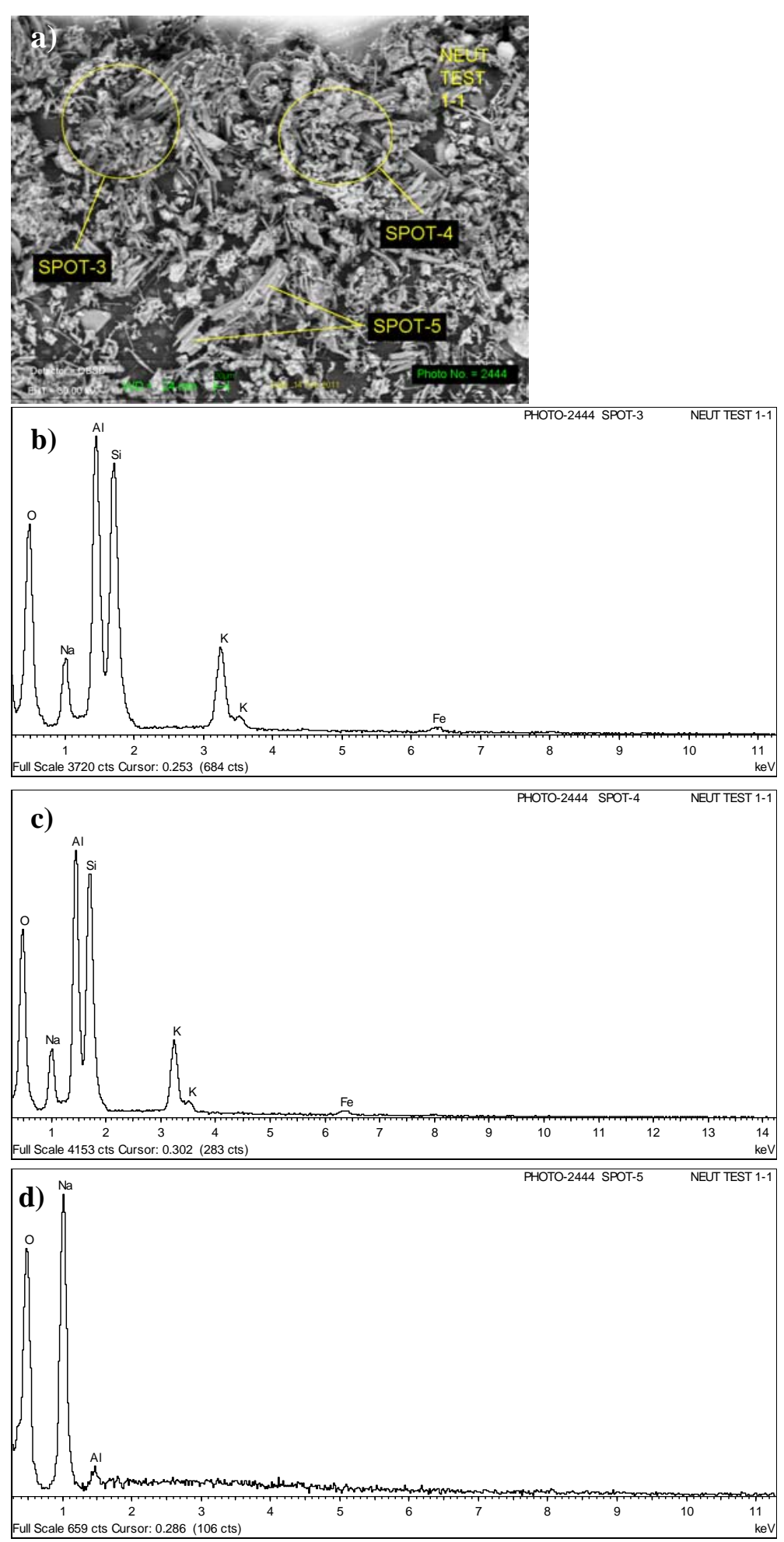

Figure C-1. a) SEM image of solids from Test 1-1. b,c,d) EDS spectra of spots 3, 4, and 5, respectively. 
SRNL-STI-2011-00316

Revision 0
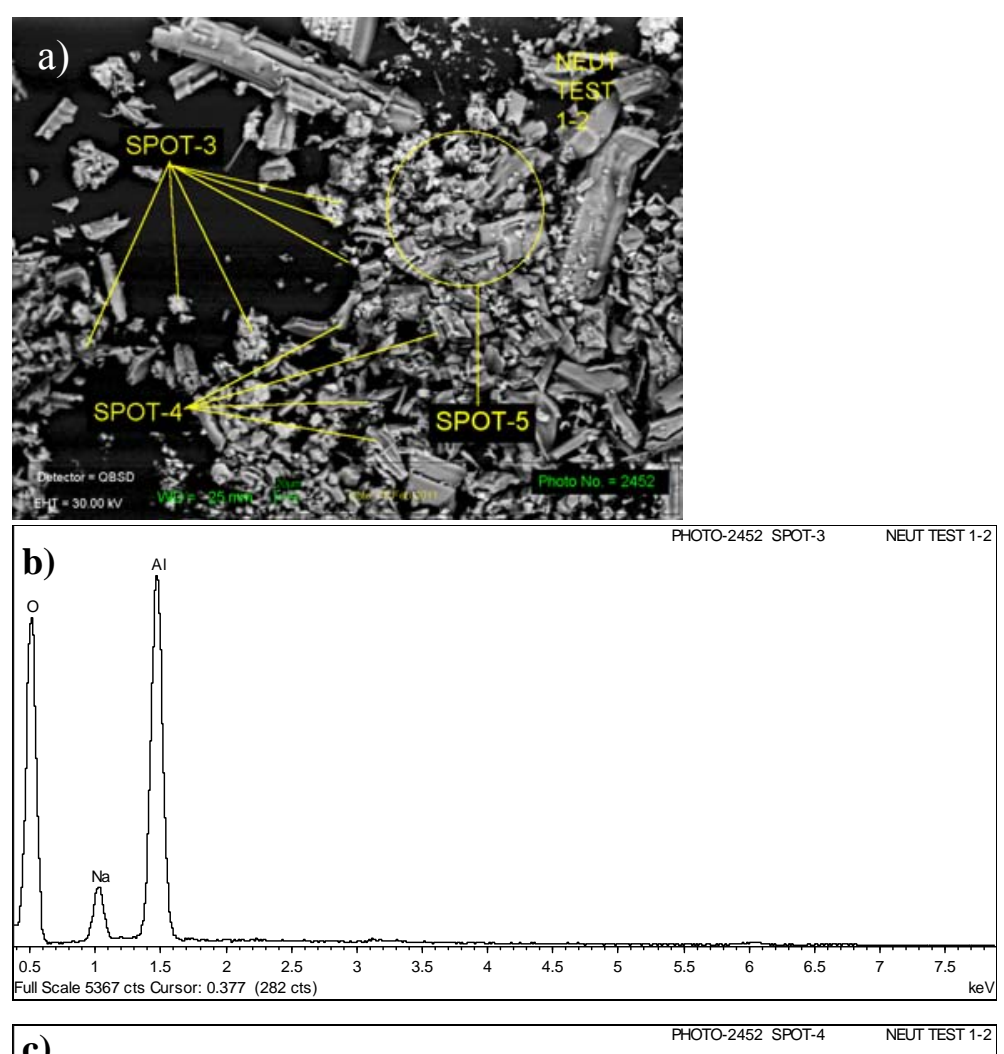

c)
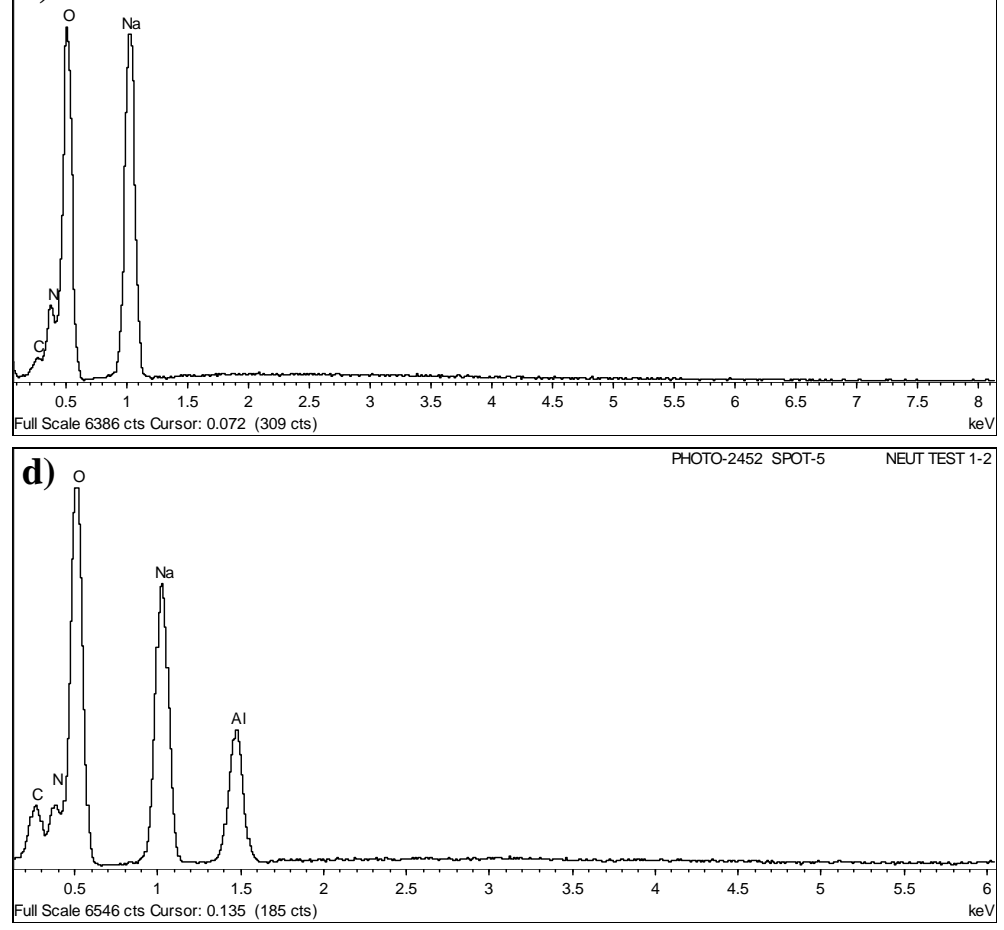

Figure C-2. a) SEM image of solids from Test 1-2. b,c,d) EDS spectra of spots 3, 4, and 5, respectively. 

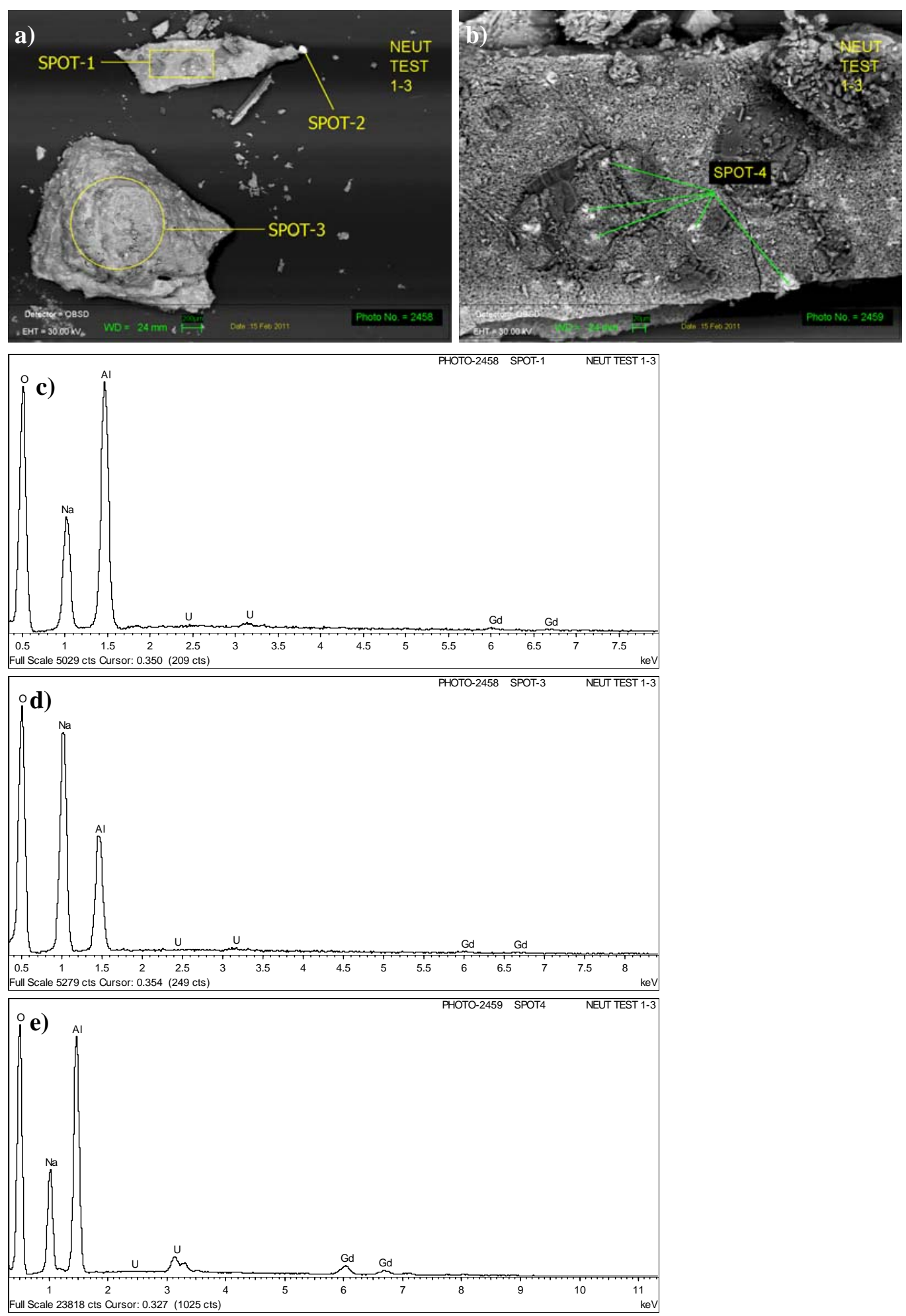

Figure C-3. a,b) SEM images of solids from Test 1-3. c,d,e) EDS spectra of spots 1, 3, and 4, respectively. 

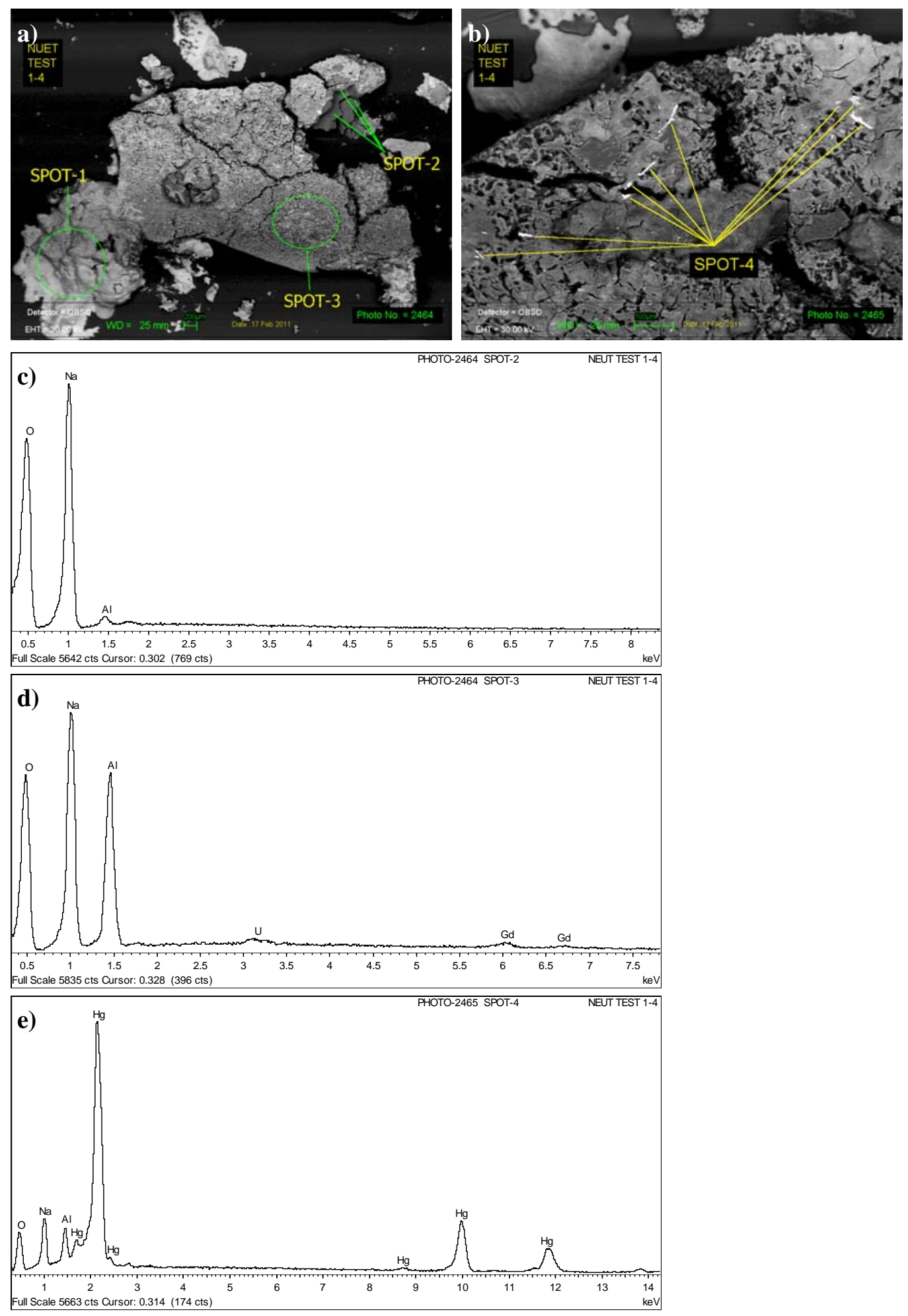

Figure C-4. a,b) SEM images of solids from Test 1-4. c,d,e) EDS spectra of spots 2, 3, and 4, respectively. 

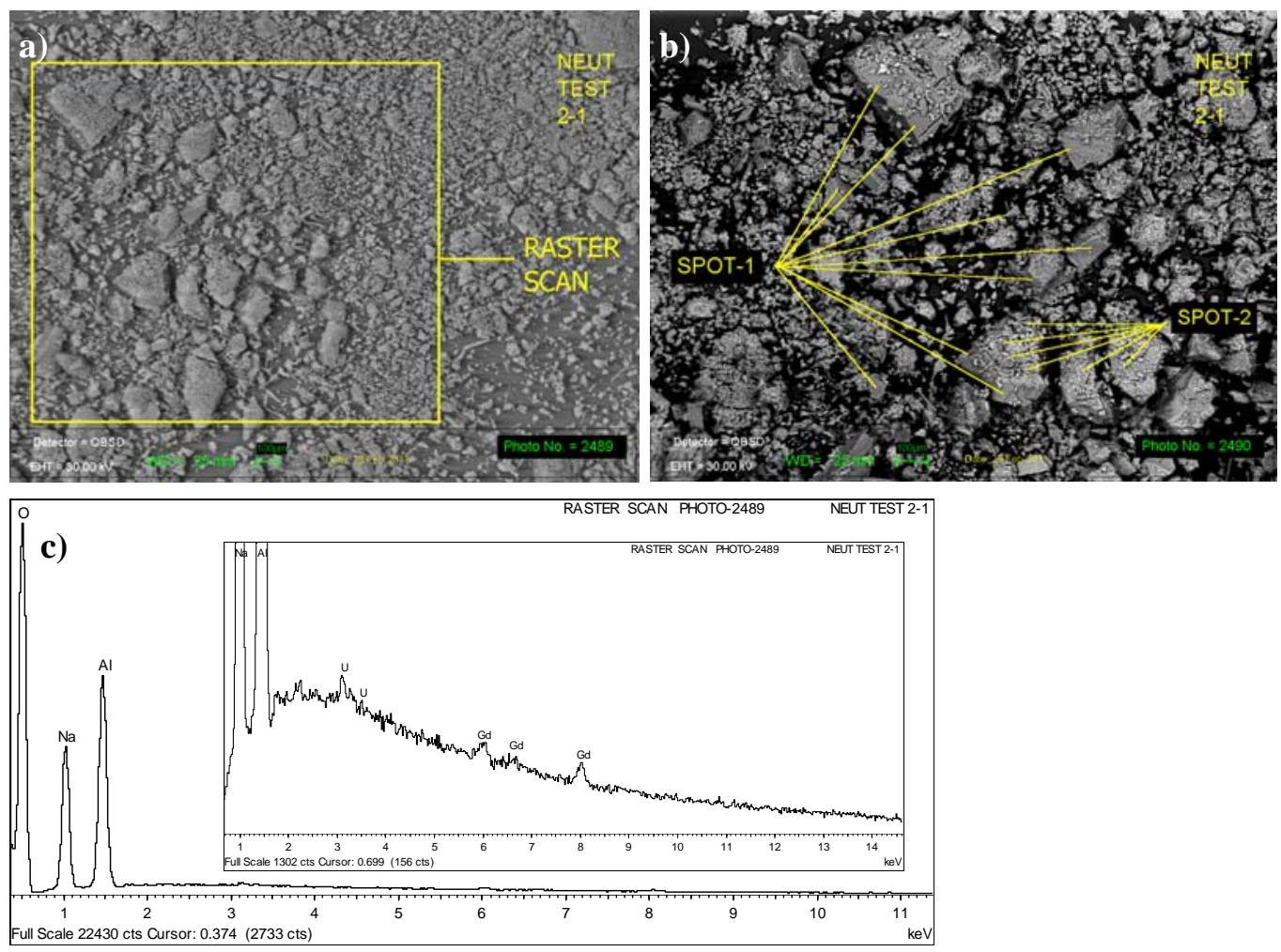

d)
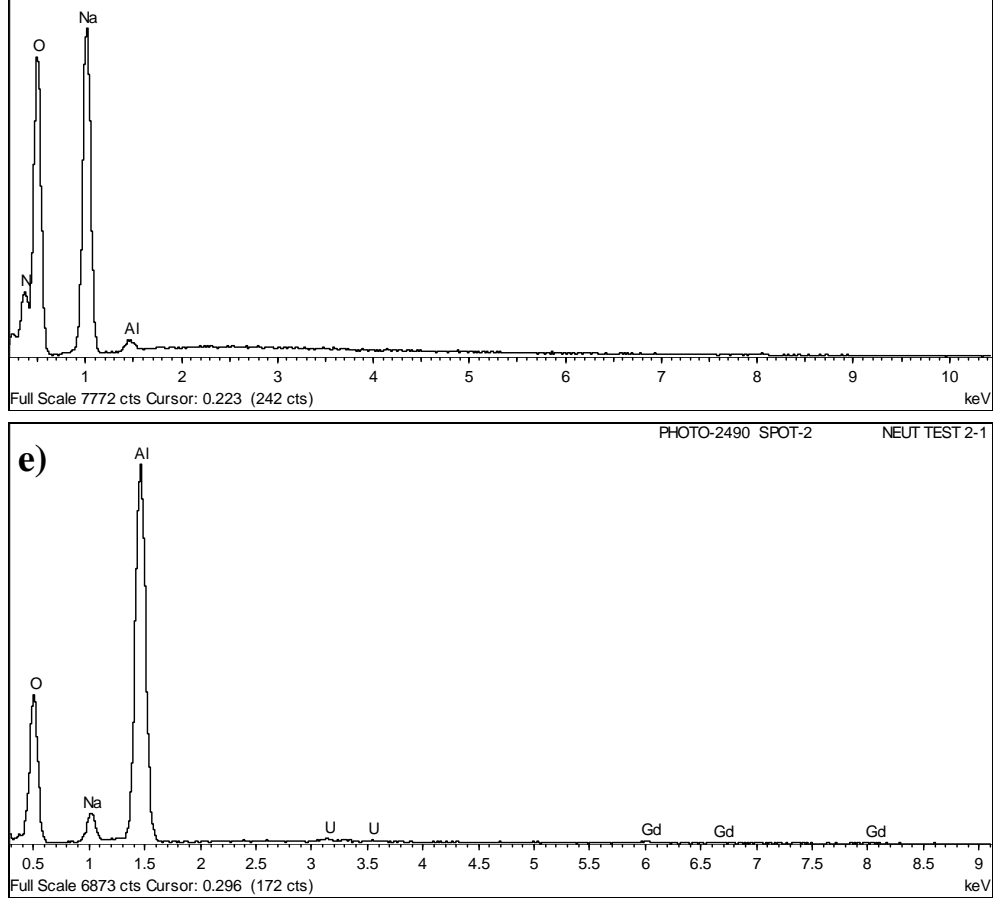

Figure C-5. a,b) SEM images of solids from Test 2-1. c) EDS spectra from raster scan. Inset shows expanded region focusing on $U$ and Gd peaks. d,e) EDS spectra of spots 1 and2, respectively. 
SRNL-STI-2011-00316

Revision 0
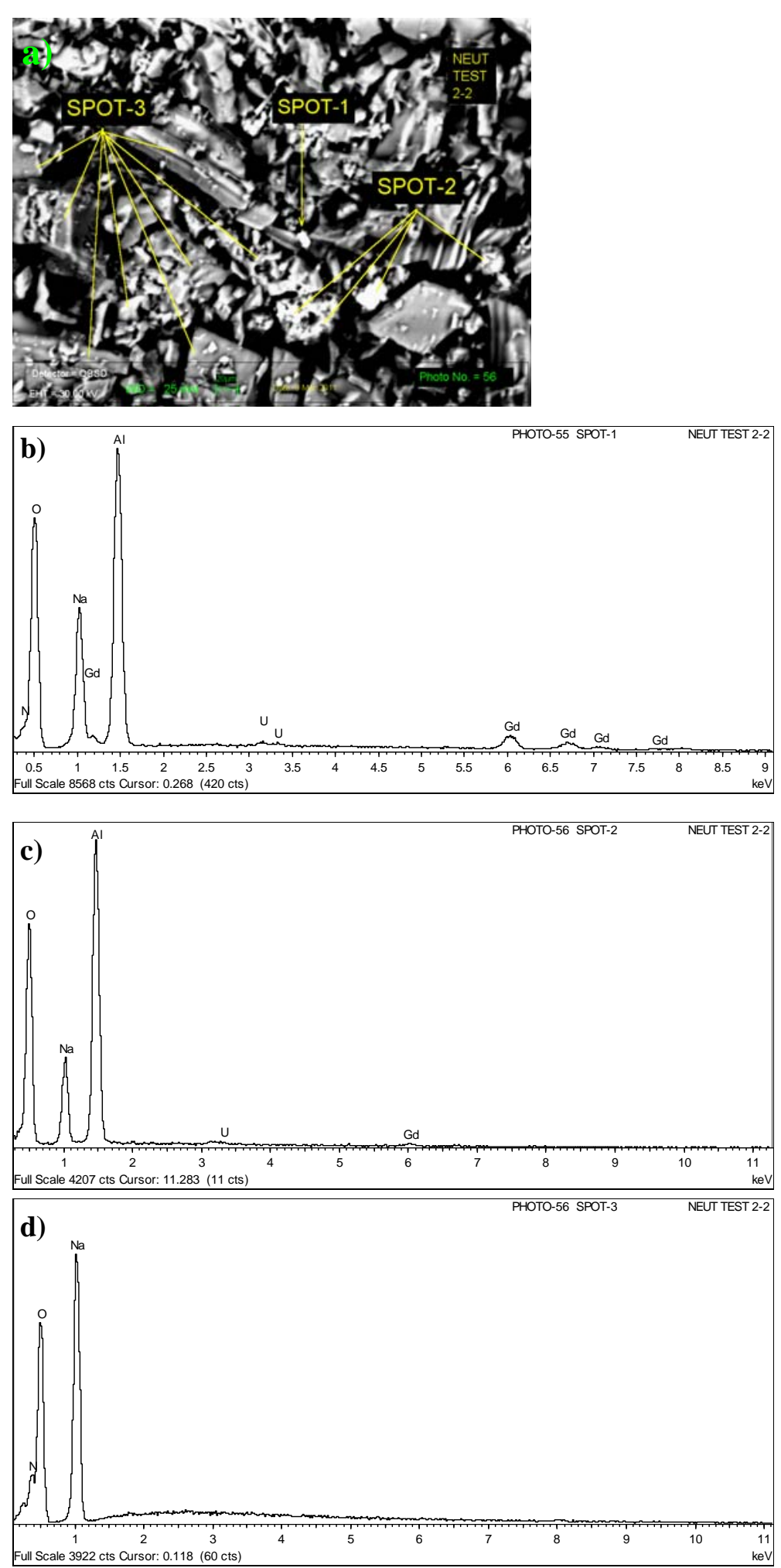

Figure C-6. a) SEM image of solids from Test 2-2. b,c,d) EDS spectra of spots 1, 2, and 3, respectively. 

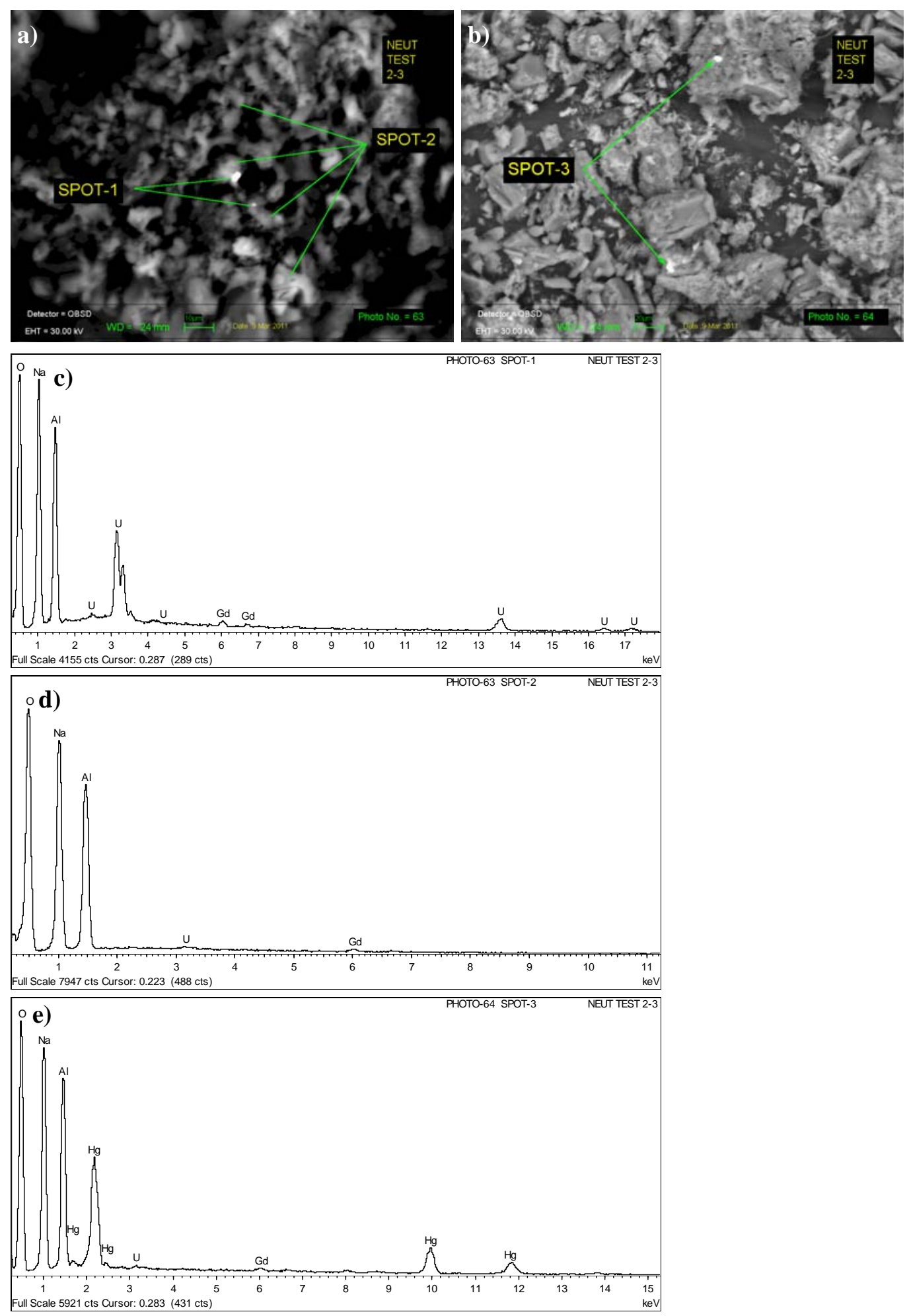

Figure C-7. a,b) SEM images of solids from Test 2-3. c,d,e) EDS spectra of spots 1, 2, and 3, respectively. 
SRNL-STI-2011-00316

Revision 0
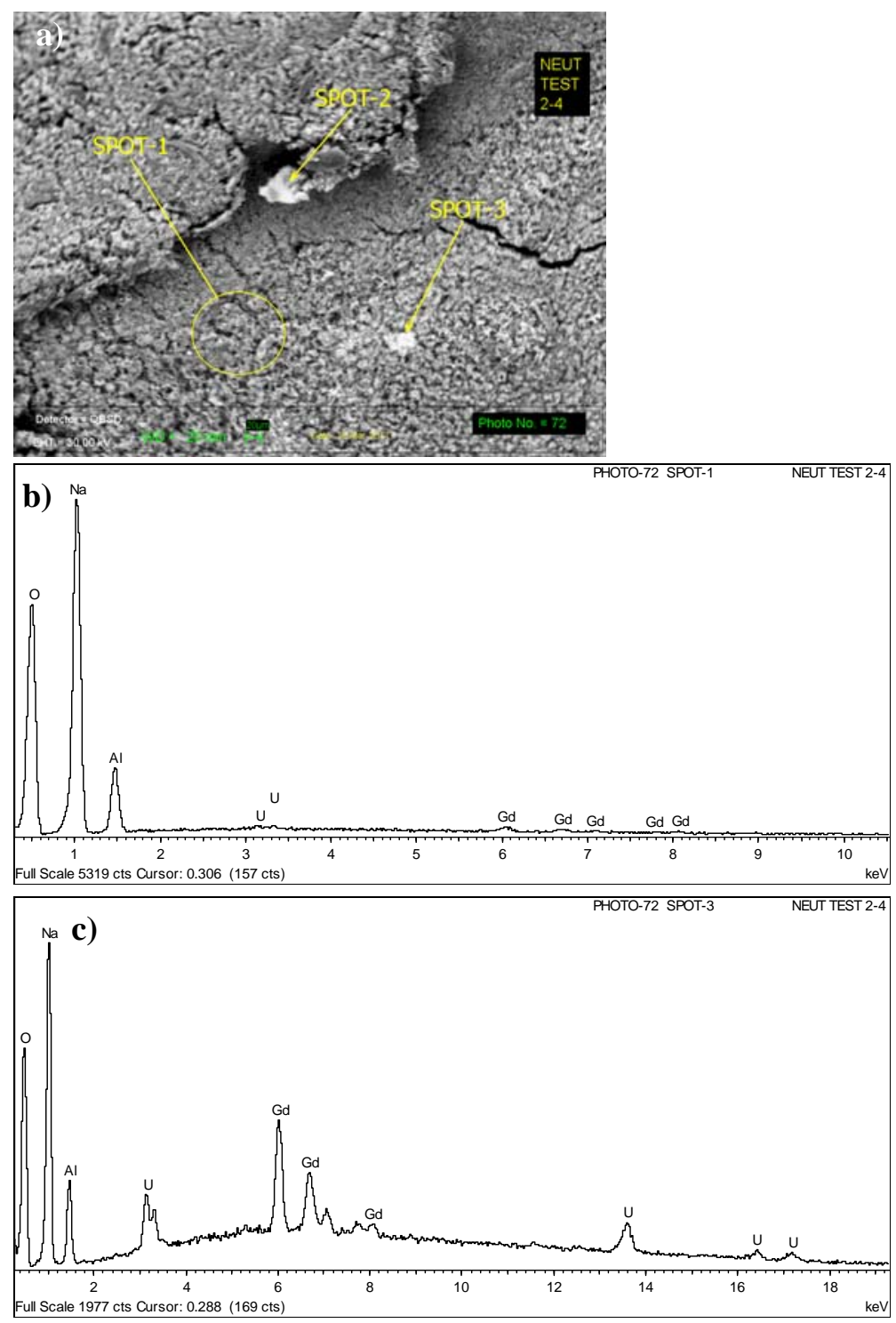

Figure C-8. a) SEM image of solids from Test 2-4. b,c) EDS spectra of spots 1 and 3, respectively. 

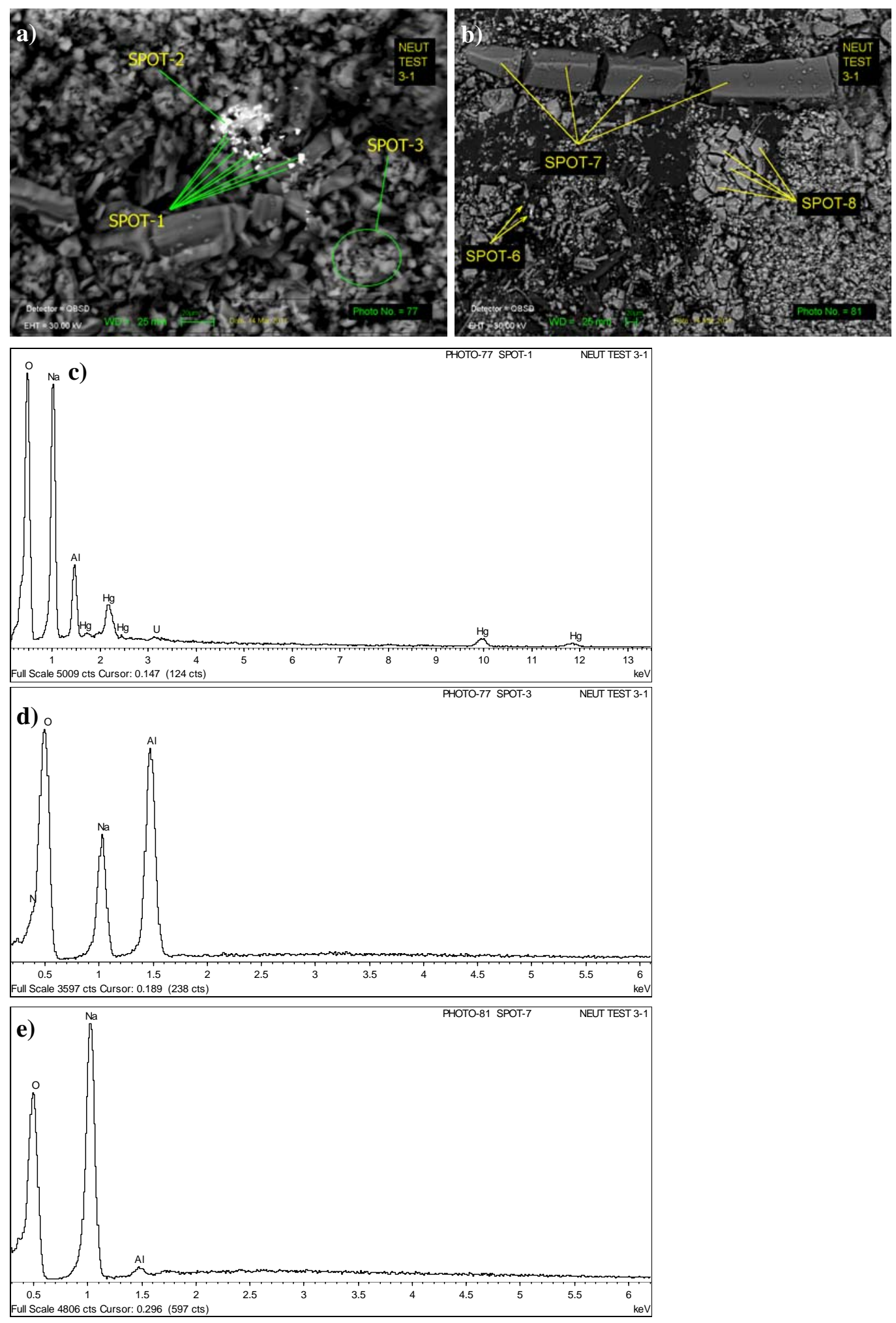

Figure C-9. a,b) SEM images of solids from Test 3-1. c,d,e) EDS spectra of spots 1, 3, and 7, respectively. 
SRNL-STI-2011-00316

Revision 0
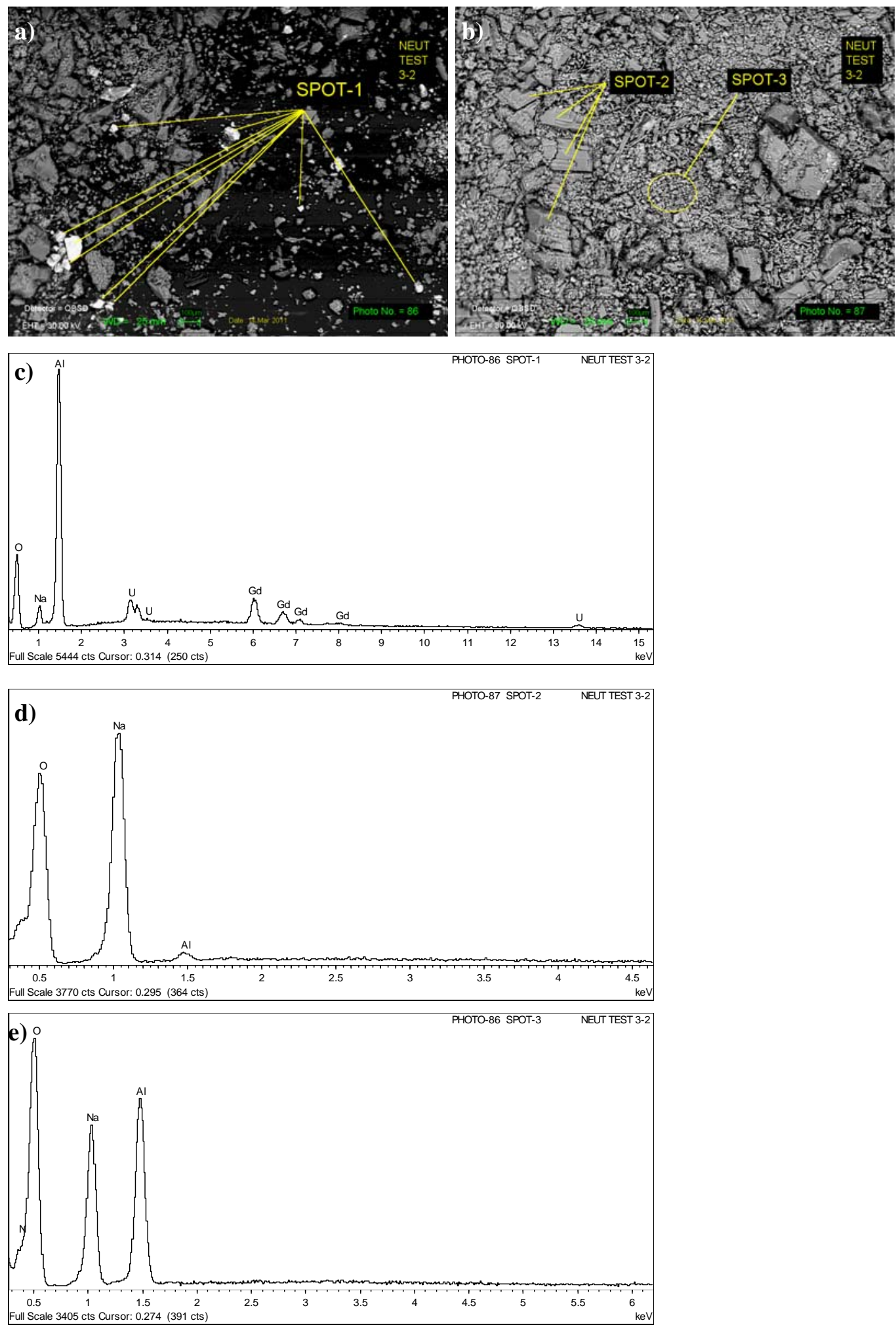

Figure C-10. a,b) SEM images of solids from Test 3-2. c,d,e) EDS spectra of spots 1, 2, and 3 , respectively. 

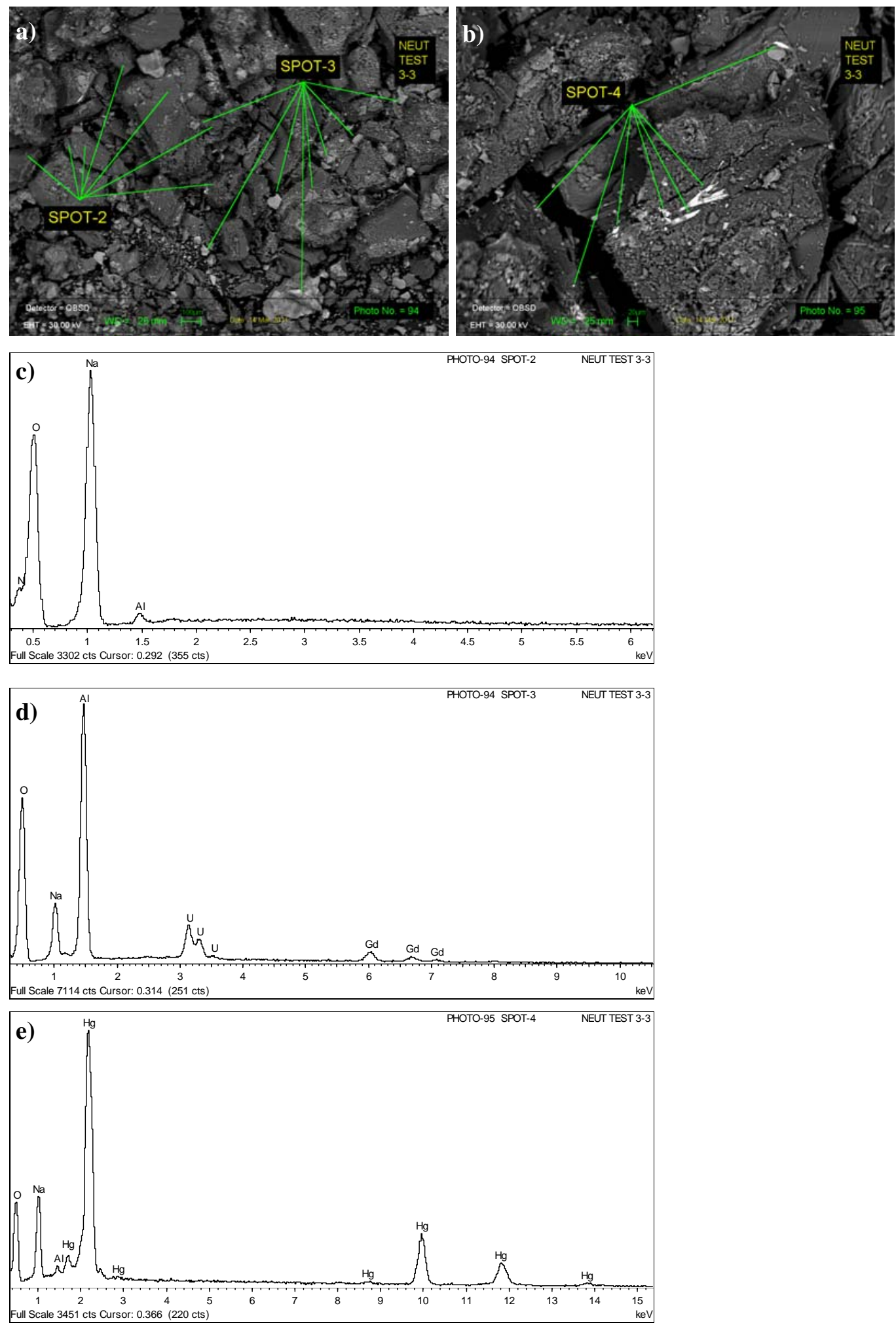

Figure C-11. a,b) SEM images of solids from Test 3-3. c,d,e) EDS spectra of spots 2, 3, and 4 , respectively. 

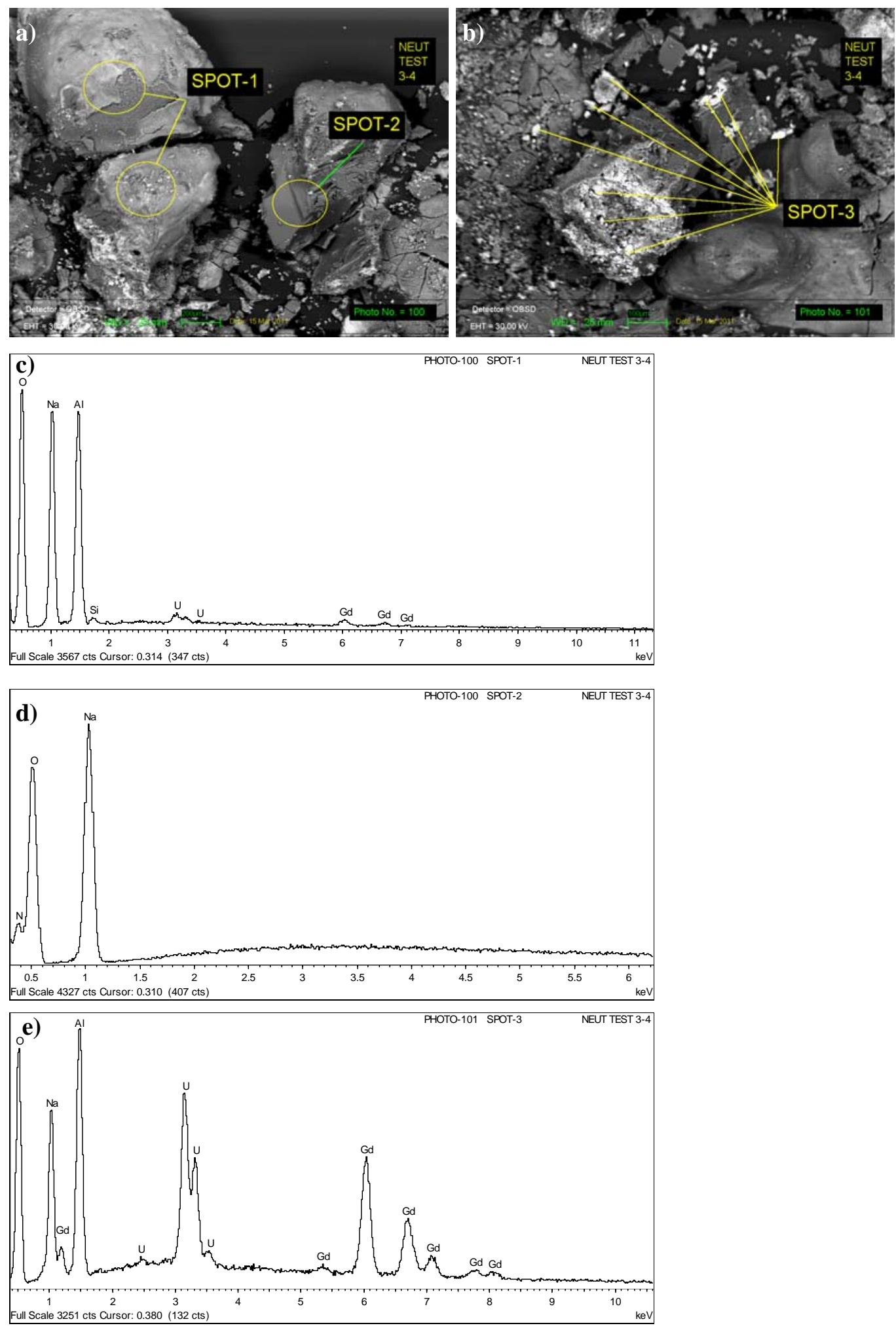

Figure C-12. a,b) SEM images of solids from Test 3-4. c,d,e) EDS spectra of spots 1, 2, and 3 , respectively. 
SRNL-STI-2011-00316

Revision 0

Appendix D 
SRNL-STI-2011-00316

Revision 0

\section{Appendix D: Sample Calculations for H:U Ratios Using Data from Thermogravimetric Analyses}

Following the neutralization of the simulant solutions to the desired endpoints with $50 \mathrm{wt} \%$ $\mathrm{NaOH}, 1.5 \mathrm{~mL}$-aliquots of the well mixed precipitate slurries were centrifuged for 5 minutes. The supernate was removed and the solids were dissolved in $1 \mathrm{~mL}$ of $8 \mathrm{M} \mathrm{HNO}_{3}$. The resulting solutions were analyzed for $\mathrm{U}, \mathrm{Gd}$, and Al. Analytical results for the solutions are given in Table B-1.

Aliquots of the well mixed precipitate slurries from the final 2 endpoints $(0.8 \mathrm{M}$ and $1.2 \mathrm{M}$ free hydroxide) for each simulant were also centrifuged and the supernate removed. Samples of these solids were then heated at $10{ }^{\circ} \mathrm{C} / \mathrm{min}$ to $750{ }^{\circ} \mathrm{C}$ using a TGA-MS. The mass of the sample at $300{ }^{\circ} \mathrm{C}$, when all waters of hydration are removed, was used along with the data in Table B-1 to calculate the H:U ratios as shown below. An example calculation is shown for the solids from Test 1-3.

The compounds present in the solids were assumed to be $\mathrm{Na}_{2} \mathrm{U}_{2} \mathrm{O}_{7}$, gadolinium hydroxide $\left(\mathrm{Gd}(\mathrm{OH})_{3}\right)$, and aluminum hydroxide $\left(\mathrm{Al}(\mathrm{OH})_{3}\right)$.

Using a basis of $1 \mathrm{~L}$ of solution, the total mmoles of solids are calculated from the concentration data in Table B-1.

$$
\begin{aligned}
& \frac{24200 \mathrm{mg} \mathrm{Al}}{L} \times 1 \mathrm{~L} \times \frac{1 \mathrm{mmol}}{26.928 \mathrm{mg}} \times \frac{1 \mathrm{mmol} \mathrm{Al}(\mathrm{OH})_{3}}{1 \mathrm{mmol} \mathrm{Al}}=898.69 \mathrm{mmol} \mathrm{Al}(\mathrm{OH})_{3} \\
& \frac{1640 \mathrm{mg} \mathrm{Gd}}{\mathrm{L}} \times 1 \mathrm{~L} \times \frac{1 \mathrm{mmol}}{157.25 \mathrm{mg}} \times \frac{1 \mathrm{mmol} \mathrm{Gd}(\mathrm{OH})_{3}}{1 \mathrm{mmol} \mathrm{Gd}}=10.43 \mathrm{mmol} \mathrm{Gd}(\mathrm{OH})_{3} \\
& \frac{1400 \mathrm{mg} \mathrm{U}}{L} \times 1 \mathrm{~L} \times \frac{1 \mathrm{mmol}}{238 \mathrm{mg}} \times \frac{1 \mathrm{mmol} \mathrm{Na} \mathrm{U}_{2} \mathrm{O}_{7}}{2 \mathrm{mmol} \mathrm{U}}=2.94 \mathrm{mmol} \mathrm{Na}_{2} \mathrm{U}_{2} \mathrm{O}_{7}
\end{aligned}
$$

The total mmoles of solids are $912.06 \mathrm{mmol}$.

Mole fractions for each of the compounds in the solids are calculated using the total number of mmoles.

$$
\begin{array}{ll}
\mathrm{Al}(\mathrm{OH})_{3} & \frac{898.69 \mathrm{mmol}}{912.06 \mathrm{mmol}}=0.98534 \\
\mathrm{Gd}(\mathrm{OH})_{3} & \frac{10.43 \mathrm{mmol}}{912.06 \mathrm{mmol}}=0.01144 \\
\mathrm{Na}_{2} \mathrm{U}_{2} \mathrm{O}_{7} & \frac{2.94 \mathrm{mmol}}{912.06 \mathrm{mmol}}=0.00322
\end{array}
$$

The average molecular weight for the solids is calculated using the mole fractions and the molecular weight of each compound.

$$
(0.98534)\left(\frac{78.00 \mathrm{mg}}{\mathrm{mmol}}\right)+(0.01144)\left(\frac{208.27 \mathrm{mg}}{\mathrm{mmol}}\right)+(0.00322)\left(\frac{633.97 \mathrm{mg}}{\mathrm{mmol}}\right)=\frac{81.28 \mathrm{mg}}{\mathrm{mmol}}
$$

The mass of dry solids (at $300{ }^{\circ} \mathrm{C}$ ) is $49.71 \mathrm{mg} \times 0.4782=23.77 \mathrm{mg}$. The water content of the solids is $49.71 \mathrm{mg}-23.77 \mathrm{mg}=25.94 \mathrm{mg}$. 
The total mmoles of $\mathrm{H}$ are calculated from the water content of the solids.

$25.94 \mathrm{mg} \mathrm{H}_{2} \mathrm{O} \times \frac{1 \mathrm{mmol}}{18.02 \mathrm{mg}} \times \frac{2 \mathrm{mmol} \mathrm{H}}{\mathrm{mmol} \mathrm{H}_{2} \mathrm{O}}=2.879 \mathrm{mmol} \mathrm{H}$

The mmoles of $U$ are calculated using the mass of the dry solids and the average molecular weight.

$23.77 \mathrm{mg} \times \frac{1 \mathrm{mmol}}{81.28 \mathrm{mg}} \times \frac{0.00322 \mathrm{mmol} \mathrm{Na} \mathrm{U}_{2} \mathrm{O}_{7}}{\mathrm{mmol} \mathrm{solids}} \times \frac{2 \mathrm{mmol} \mathrm{U}}{\mathrm{mmol} \mathrm{Na}_{2} \mathrm{U}_{2} \mathrm{O}_{7}}=0.00188 \mathrm{mmol} \mathrm{C}$

The H:U ratio is calculated below:

$\frac{H}{U}=\frac{2.879 \mathrm{mmol} \mathrm{H}}{0.00188 \mathrm{mmol} U}=1531$ 


\section{Appendix E}




\section{Appendix E: Sample Calculations for H:U Ratios Using Data from Graduated Cylinder Experiments}

The mass and volume measurements recorded during the graduated cylinder tests are shown in Tables E-1 and E-2. These data are used to calculate the H:U ratios for solids produced during the neutralization experiments after settling for nominally 1 week.

Table E-1. Graduated Cylinder Mass and Volume Measurements

\begin{tabular}{|c|c|c|c|c|c|}
\hline Test & $\begin{array}{c}\text { Mass of Empty } \\
\text { Graduated } \\
\text { Cylinder (g) }\end{array}$ & $\begin{array}{c}\text { Mass of Grad. } \\
\text { Cylind. + Precipitate } \\
\text { Slurry (g) }\end{array}$ & $\begin{array}{c}\text { Volume of } \\
\text { Precipitate } \\
\text { Slurry (mL) }\end{array}$ & $\begin{array}{c}\text { Volume of } \\
\text { Settled } \\
\text { Solids (mL) }\end{array}$ & $\begin{array}{c}\text { Vol. of Solids + Solution } \\
\text { after Supernate Removal } \\
(\mathbf{m L})\end{array}$ \\
\hline $\mathbf{1 - 3}$ & 55.860 & 89.528 & 23.4 & 11.2 & 12.6 \\
\hline $\mathbf{1 - 4}$ & 56.293 & 91.077 & 24.6 & 19.9 & 20.4 \\
\hline $\mathbf{2 - 3}$ & 56.877 & 91.752 & 24.8 & 22.2 & 22.6 \\
\hline $\mathbf{2 - 4}$ & 55.725 & 90.512 & 24.4 & 17.2 & 18.0 \\
\hline $\mathbf{3 - 3}$ & 56.168 & 89.053 & 24.6 & 7.0 & 7.6 \\
\hline $\mathbf{3 - 4}$ & 56.511 & 89.852 & 24.8 & 4.0 & 5.2 \\
\hline
\end{tabular}

Table E-2. Beaker and Graduated Cylinder Mass Measurements

\begin{tabular}{|c|c|c|c|c|c|c|c|c|}
\hline Test & $\begin{array}{c}\text { Mass of } \\
\text { Empty } \\
\text { Supernate } \\
\text { Beaker (g) }\end{array}$ & $\begin{array}{c}\text { Mass of } \\
\text { Empty } \\
\text { Solids } \\
\text { Beaker } \\
\text { (g) }\end{array}$ & $\begin{array}{c}\text { Mass of } \\
\text { Beaker + } \\
\text { Supernate } \\
\text { (g) }\end{array}$ & $\begin{array}{c}\text { Mass of Grad. } \\
\text { Cyl. After } \\
\text { Removing } \\
\text { Supernate (g) }\end{array}$ & $\begin{array}{c}\text { Mass of } \\
\text { Beaker } \\
\text { + Solids } \\
\text { (g) }\end{array}$ & $\begin{array}{c}\text { Mass of } \\
\text { Beaker + } \\
\text { Solids and } \\
\text { Rinse } \\
\text { Water (g) }\end{array}$ & $\begin{array}{c}\text { Mass of } \\
\text { Dry } \\
\text { Supernate } \\
\text { Beaker (g) }\end{array}$ & $\begin{array}{c}\text { Mass of } \\
\text { Dry } \\
\text { Solids } \\
\text { Beaker } \\
\text { (g) }\end{array}$ \\
\hline $\mathbf{1 - 3}$ & 50.212 & 29.533 & 65.057 & 74.662 & 38.038 & 68.848 & 58.616 & 48.225 \\
\hline $\mathbf{1 - 4}$ & 49.209 & 49.853 & 54.856 & 85.398 & 78.023 & 83.797 & 52.452 & 74.446 \\
\hline $\mathbf{2 - 3}$ & 30.271 & 50.844 & 33.304 & 88.706 & 81.480 & 91.495 & 31.951 & 79.650 \\
\hline $\mathbf{2 - 4}$ & 50.262 & 29.583 & 59.256 & 81.500 & 53.950 & 61.067 & 55.852 & 53.215 \\
\hline $\mathbf{3 - 3}$ & 28.223 & 30.190 & 50.802 & 66.462 & 39.534 & 49.766 & 41.617 & 38.586 \\
\hline $\mathbf{3 - 4}$ & 30.293 & 50.101 & 56.249 & 63.861 & 56.629 & 63.070 & 46.510 & 55.110 \\
\hline
\end{tabular}

Sample calculations for the $\mathrm{H}: \mathrm{U}$ ratios following one week of settling for solids precipitated during full neutralization (1.2 M free hydroxide) of Simulant 1 (test 1-4) are summarized below.

Initial Mass of Slurry $=($ Grad. Cyliner + Precip. Slurry Mass) $-($ Grad. Cylinder Mass $)$

Initial Mass of Slurry $=91.077 \mathrm{~g}-56.293 \mathrm{~g}=34.784 \mathrm{~g}$

Slurry Density $=\frac{\text { Initial Mass of Slurry }}{\text { Volume Precipitate Slurry }}$

Slurry Density $=\frac{34.784 \mathrm{~g}}{24.6 \mathrm{~mL}}=1.414 \frac{\mathrm{g}}{\mathrm{mL}}$

Preliminary Calculations for Supernate Water

Vol. Super.to Beaker $=($ Vol. Precip. Slurry $)-($ Vol. Solids + Soln. Following Super. Removal $)$

Vol. Super.to Beaker $=24.6 \mathrm{~mL}-20.4 \mathrm{~mL}=4.2 \mathrm{~mL}$

Mass Super.to Beaker $=($ Mass of Beaker + Supernate $)-($ Mass of Empty Super. Beaker $)$

Mass Super.to Beaker $=54.856 \mathrm{~g}-49.209 \mathrm{~g}=5.647 \mathrm{~g}$ 
Density of Supernate $=\frac{\text { Mass Super.to Beaker }}{\text { Vol. Super.to Beaker }}$

Density of Supernate $=\frac{5.647 \mathrm{~g}}{4.2 \mathrm{~mL}}=1.345 \frac{\mathrm{g}}{\mathrm{mL}}$

Mass $\mathrm{H}_{2} \mathrm{O}$ in Super.to Beaker $=($ Mass of Beaker + Super. $)-($ Mass of Dry Super. Beaker $)$

Mass $\mathrm{H}_{2} \mathrm{O}$ in Super.to Beaker $=54.856 \mathrm{~g}-52.452 \mathrm{~g}=2.404 \mathrm{~g}$

$\frac{\text { Mass } \mathrm{H}_{2} \mathrm{O}}{\text { Vol. Supernate }}=\frac{\text { Mass } \mathrm{H}_{2} \mathrm{O} \text { in Super.to Beaker }}{\text { Vol. Super.to Beaker }}$

$\frac{\text { Mass } \mathrm{H}_{2} \mathrm{O}}{\text { Vol. Supernate }}=\frac{2.404 \mathrm{~g}}{4.2 \mathrm{~mL}}=0.572 \frac{\mathrm{g}}{\mathrm{mL}}$

Preliminary Calculations for Solids Water

Mass of Precip. Slurry Left in Grad.Cyl.=(Mass Grad.Cyl.after Remov. Super.) -(Mass Grad.Cyl.)

Mass of Precip. Slurry Left in Grad.Cyl $=85.398 \mathrm{~g}-56.293 \mathrm{~g}=29.105 \mathrm{~g}$

Mass Precip. Slurry $+\mathrm{H}_{2} \mathrm{O}$ in Beaker $=\left(\right.$ Mass of Beaker + Solids $\left.+\mathrm{H}_{2} \mathrm{O}\right)-($ Mass of Empty Solids Beaker $)$

Mass Precip. Slurry $+\mathrm{H}_{2} \mathrm{O}$ in Beaker $=83.797 \mathrm{~g}-49.853 \mathrm{~g}=33.944 \mathrm{~g}$

Mass of Rinse $\mathrm{H}_{2} \mathrm{O}$ Used $=$ (Mass of Precip. Slurry $+\mathrm{H}_{2} \mathrm{O}$ in Beaker $)-($ Mass of Beaker + Solids $)$

Mass of Rinse $\mathrm{H}_{2} \mathrm{OUsed}=83.797 \mathrm{~g}-78.023 \mathrm{~g}=5.774 \mathrm{~g}$

$\underline{\text { Water in Supernate Above Solids }}$

Mass of Super. Left in Grad.Cyl. $=[($ Vol. Solids + Soln.after Remov. Super. $)-$ (Vol. Settled Solids)] $\times($ Density of Super.)

Mass of Super. Left in Grad.Cyl. $=[20.4 \mathrm{~mL}-19.9 \mathrm{~mL}] \times\left[\frac{1.345 \mathrm{~g}}{\mathrm{~mL}}\right]=0.672 \mathrm{~g}$

Mass of Super. $\mathrm{H}_{2} \mathrm{O}$ Left in Grad. Cyl. $=[($ Vol. Solids + Soln. after Remov. Super. $)-$

$$
\text { (Vol.Settled Solids) }] \times\left[\frac{\text { Mass } \mathrm{H}_{2} \mathrm{O}}{\text { Vol.Super. }}\right]
$$

Mass of Super. $\mathrm{H}_{2} \mathrm{O}$ Left in Grad. Cyl. $=[20.4 \mathrm{~mL}-19.9 \mathrm{~mL}] \times\left[\frac{0.572 \mathrm{~g}}{\mathrm{~mL}}\right]=0.286 \mathrm{~g}$

Water in Settled Solids

Mass of Dry Solids in Beaker $=($ Mass of Dry Solids Beaker $)-($ Mass of Empty Solids Beaker $)$

Mass of Dry Solids in Beaker $=74.446 \mathrm{~g}-49.853 \mathrm{~g}=24.593 \mathrm{~g}$

Mass of $\mathrm{H}_{2} \mathrm{O}$ Evap. from Beaker $=\left(\right.$ Mass Precip. Slurry $+\mathrm{H}_{2} \mathrm{O}$ in Beaker $)-($ Mass of Dry Solids Beaker $)$

Mass of $\mathrm{H}_{2} \mathrm{O}$ Evap. from Beaker $=83.797 \mathrm{~g}-74.446 \mathrm{~g}=9.351 \mathrm{~g}$ 
Mass of $\mathrm{H}_{2} \mathrm{O}$ in Solids $=\left(\right.$ Mass of $\mathrm{H}_{2} \mathrm{O}$ Evap. from Beaker $)-\left(\right.$ Mass of Rinse $\left.\mathrm{H}_{2} \mathrm{O}\right)$ -(Mass of Super. $\mathrm{H}_{2} \mathrm{O}$ left in Grad. Cyl.)

Mass of $\mathrm{H}_{2} \mathrm{O}$ in Solids $=9.351 \mathrm{~g}-5.774 \mathrm{~g}-0.286 \mathrm{~g}=3.291 \mathrm{~g}$

Moles of H in Settled Solids

$3.291 \mathrm{~g} \mathrm{H}_{2} \mathrm{O} \times \frac{1 \mathrm{~mol} \mathrm{H}_{2} \mathrm{O}}{18.02 \mathrm{~g} \mathrm{H}_{2} \mathrm{O}} \times \frac{2 \mathrm{~mol} \mathrm{H}}{\mathrm{mol} \mathrm{H}_{2} \mathrm{O}}=0.365$ mole $\mathrm{H}$

\section{$\underline{\text { Moles U in Solution }}$}

If the total $\mathrm{U}$ in solution precipitates,

Mass $U=24.6 \mathrm{~mL} \times \frac{1 \mathrm{~L}}{1000 \mathrm{~mL}} \times \frac{1.5 \mathrm{~g} \mathrm{U}}{\mathrm{L}} \times \frac{50 \mathrm{~mL}}{50 \mathrm{~mL}+25.6 \mathrm{~mL}}=0.024 \mathrm{~g} U$

however, ICP-ES results indicate that $>90.8 \%$ precipitates (see Table $3-2$ ).

Mass $U$ in Solids $=0.024 \mathrm{~g} \times 0.908=>0.022 \mathrm{~g} U$

$>0.022 \mathrm{~g} \mathrm{U} \times \frac{1 \mathrm{~mol} U}{238 \mathrm{gU}}=9.10 \times 10^{-5} \mathrm{~mol}$

$\underline{\text { H Ratio }}$

$\frac{H}{U}=\frac{0.365 \mathrm{~mol} \mathrm{H}}{9.10 \times 10^{-5} \mathrm{~mol} \mathrm{U}}=4015$ 
Distribution:
A. B. Barnes, 999-W
D. A. Crowley, 773-43A
S. D. Fink, 773-A
B. J. Giddings, 786-5A
C. C. Herman, 999-W
S. L. Marra, 773-A
A. M. Murray, 773-A
F. M. Pennebaker, 773-42A
W. R. Wilmarth, 773-A
K. M. L. Taylor-Pashow, 773-A
M. G. Bronikowski, 773-A
T. S. Rudisill, 773-A
W. H. Clifton, 704-2H
W. G. Dyer, 704-2H
S. L. Hudlow, 221-H
R. A. L. Eubanks, 221-H
M. C. Chandler, 703-H
J. R. Lint, 704-185H
B. M. Williamson, 704-18H
A. W. Wiggins, Jr., 704-60H
E. W. Harrison, 704-60H

W. E. Harris, 704-2H

J. B. Schaade, 704-2H

G. J. Zachman, 225-7H

P. B. Andrews, 704-2H

S. J. Howell, 704-2H

M. J. Lewczyk, 221-H

K. A. Dukes, 221-H

S. A. Thomas, 703-46A 